\title{
OPEN The removal of anionic and cationic dyes from an aqueous solution using biomass-based activated carbon
}

\begin{abstract}
Nurul Umairah M. Nizam ${ }^{1}$, Marlia M. Hanafiah $^{1,2 \bowtie}$, Ebrahim Mahmoudi ${ }^{3}$, Azhar A. Halim $^{1} \&$ Abdul Wahab Mohammad ${ }^{3,4}$

In this study, two biomass-based adsorbents were used as new precursors for optimizing synthesis conditions of a cost-effective powdered activated carbon (PAC). The PAC removed dyes from an aqueous solution using carbonization and activation by $\mathrm{KOH}, \mathrm{NaOH}$, and $\mathrm{H}_{2} \mathrm{SO}_{4}$. The optimum synthesis, activation temperature, time and impregnation ratio, removal rate, and uptake capacity were determined. The optimum PAC was analyzed and characterized using Fourier-transform infrared spectroscopy (FTIR), x-ray diffraction (XRD), a field emission scanning electron microscope (FESEM), Zeta potential, and Raman spectroscopy. Morphological studies showed single-layered planes with highly porous surfaces, especially PAC activated by $\mathrm{NaOH}$ and $\mathrm{H}_{2} \mathrm{SO}_{4}$. The results showed that the experimental data were well-fitted with a pseudo-second-order model. Based on Langmuir isotherm, the maximum adsorption capacity for removing methylene blue (MB) was $769.23 \mathrm{mg} \mathrm{g}^{-1}$ and $458.43 \mathrm{mg} \mathrm{g}^{-1}$ for congo red (CR). Based on the isotherm models, more than one mechanism was involved in the adsorption process, monolayer for the anionic dye and multilayer for the cationic dye. Elovich and intraparticle diffusion kinetic models showed that rubber seed shells (RSS) has higher $\alpha$ values with a greater tendency to adsorb dyes compared to rubber seed (RS). A thermodynamic study showed that both dyes' adsorption process was spontaneous and exothermic due to the negative values of the enthalpy $(\Delta \mathrm{H})$ and Gibbs free energy $(\Delta \mathrm{G})$. The change in removal efficiency of adsorbent for regeneration study was observed in the seventh cycles, with a $3 \%$ decline in the $C R$ and $2 \%$ decline in MB removal performance. This study showed that the presence of functional groups and active sites on the produced adsorbent (hydroxyl, alkoxy, carboxyl, and $\pi-\pi$ ) contributed to its considerable affinity for adsorption in dye removal. Therefore, the optimum PAC can serve as efficient and costeffective adsorbents to remove dyes from industrial wastewater.
\end{abstract}

Achieving sustainable water management in an integrated and cross-cutting manner is one of the most significant challenges facing many countries. Sustainable water management includes a metric for wastewater treatment, which is vital in successfully managing wastewater and, ultimately, water quality. However, water contamination from different pollutants such as dyes has become a major environmental and health problem that poses a threat to society and living organisms ${ }^{1,2}$. The high concentration of dyes in natural water sources and industrial wastewater streams is a critical issue faced by many countries. The dyes are notorious for their persistence, high toxicity, and carcinogenic impurities. They also bioaccumulate in the food chain and, hence, the human body ${ }^{3,4}$. In recent studies, numerous toxic chemicals have been detected in drinking water at dangerous levels in many parts of the world ${ }^{5-14}$. The most common toxic pollutants are harmful chemicals and dyes in wastewater produced by heavy industries and other human activities that must be treated before discharged to the environment. Treatment must be accomplished using techniques that are robust, economically feasible, and environmentally friendly ${ }^{15-20}$.

\footnotetext{
${ }^{1}$ Department of Earth Sciences and Environment, Faculty of Science and Technology, Universiti Kebangsaan Malaysia, 43600 Bangi, Selangor, Malaysia. ${ }^{2}$ Centre for Tropical Climate Change System, Institute of Climate Change, Universiti Kebangsaan Malaysia, 43600 Bangi, Selangor, Malaysia. ${ }^{3}$ Department of Chemical and Process Engineering, Universiti Kebangsaan Malaysia, 43600 Bangi, Selangor, Malaysia. ${ }^{4}$ Research Centre for Sustainable Process Technology (CESPRO), Faculty of Engineering and Built Environment, Universiti Kebangsaan Malaysia, 43600 Bangi, Selangor, Malaysia. ${ }^{\circledR}$ email: mhmarlia@ukm.edu.my
} 
Worldwide, environmental scientists' focus has been developing efficient and sustainable technologies for water and wastewater management $t^{2,21,22}$. To overcome the shortcomings of more traditional approaches, cheaper and more efficient techniques to improve the quality of treated effluent have been proposed. Some of the widelyused methods include adsorption, membrane filtration, coagulation and flocculation, chemical precipitation, ion exchange, electrochemical removal, biosorption, reverse osmosis, and oxidation processes ${ }^{7,17.23-28}$. However, most of those methods involve high operational and maintenance costs. Among the techniques mentioned, the adsorption process using local biowastes is a cost-effective and efficient technique for removing toxic dyes and metal ions from wastewater ${ }^{17}$. Dyes are widely used in textile, food, printing, leather, and pharmacology industries ${ }^{29-31}$. The presence of dyes in aqueous solutions and the environment can affect the photosynthetic functions of plants in water by blocking the sunlight with its aromatic compounds and reducing dissolved oxygen ${ }^{29,31-34}$. Plus, some dyes, especially cationic and anionic, are also carcinogenic and mutagenic that can affect digestive tract irritation, skin irritation, and cyanosis ${ }^{28-32}$. In addition, cationic dyes like $\mathrm{MB}$ and anionic dyes such as $\mathrm{CR}$ are the most widely used dyes in industries ${ }^{31}$. Thus, it is crucial to control the release of these compounds to the environment.

The adsorption method typically uses activated carbon from natural resources that have high carbon content. Activated carbon is widely used to remove dyes from wastewater because of its convenience, ease of operation, simplicity of design, and reusability ${ }^{1-3,35-37}$. However, despite its extensive use in wastewater treatment, some commercial activated carbon remains an expensive material ${ }^{35-37}$. Therefore, interest in lower-cost alternatives to commercially available activated carbon that would still provide safe and economical methods of removing dyes from contaminated water has increased. For this reason, low-cost by-products of agriculture that able to act as an adsorbent have been recognized as a sustainable solution for wastewater treatment that minimizes waste, recovery, and reuse $\mathrm{e}^{6,15,17,21-24,38}$. To support the sustainable option for removing dyes, PAC has been synthesized from rubber seed (RS) and its shell (RSS). These are one of the most common biomass wastes produced in Malaysia. RS and RSS are the waste by-products of agriculture and are generated consistently in bulk ${ }^{39}$. Thus, the synthesis of PAC from a different kind of biomass like RS and RSS has been extensively explored in the water treatment field. Therefore, PAC derived from RS and RSS can provide a high surface area and a specific affinity for the adsorption of dyes from aqueous systems ${ }^{1,16,40-43}$.

RSS has a smooth and impervious texture due to its chemical composition, influencing the PACs' properties. Therefore, the study of possible effects of this biomass pretreatment may indicate the best way to produce PACs

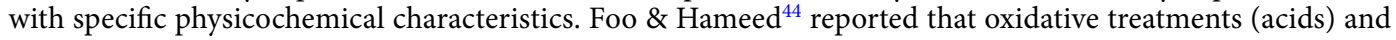
base treatments (alkaline) are excellent activation agents for activated carbon (AC) preparation. Oxidative treatment using acids can be associated with enhanced acidic functional groups (carboxylic, phenol, and carbonyl groups) on the AC surface. In contrast, basic treatment tends to have relatively large ion exchange capacities due to alkalinity and abundance of - $\mathrm{OH}$ groups. However, most of the related studies used only either one of the pretreatment methods mentioned ${ }^{1,2,16,20,35,37,39-43,45}$. To acknowledge the gap in this area, this study investigated the systematic effect of pretreatment using both acidic and basic activating agents to compare the characteristics using multiple characterization analyses.

This study focused on developing optimum operating conditions to synthesize PAC from RS and RSS for dye removal from aqueous solutions using carbonization, $\mathrm{KOH}, \mathrm{NaOH}$, and $\mathrm{H}_{2} \mathrm{SO}_{4}$ activation. The requirements for removal and uptake capacity, such as the effects of an adsorbent dose, $\mathrm{pH}$, and time were studied. In addition, under optimum conditions, PAC was analyzed and characterized using physio-chemical techniques such as Fourier-transform infrared spectroscopy (FTIR), XRD, X-ray fluorescence (XRF), a FESEM, Zeta potential, and Raman spectroscopy. The operating conditions for the adsorption of dyes were optimized. In contrast, the studies of kinetics and isothermal behavior of adsorption and thermodynamic analysis were conducted under optimized conditions. The performance of the RS and RSS-derived adsorbents was compared. The results of those studies provided a better understanding of the mechanism for the adsorption of dye molecules onto the prepared PAC.

\section{Results and discussion}

Characterization of the synthesized PAC. The XRD spectra of the PACs are shown in Fig. 1a-b. A broad diffraction peak of approximately $23.5^{\circ}$ for all solutions corresponded to the activated carbon structure's crystal plane. Spectra of RSS $\mathrm{H}_{2} \mathrm{SO}_{4}$ showed two strong peaks at $23.0^{\circ}$ and $23.8^{\circ}$, one strong peak for $\mathrm{NaOH}$, and no strong $\mathrm{KOH}$ peaks. In the spectrum of $45.1^{\circ}$ of $\mathrm{H}_{2} \mathrm{SO}_{4}, 45.0^{\circ}$ of $\mathrm{NaOH}$, and $44.5^{\circ}$ of $\mathrm{KOH}$, there were new and characteristic peaks, implying the existence of the PAC in metallic form. Based on the weakest peak and intensity shown, the $\mathrm{KOH}$ solution was the least effective among the three solutions for RSS, while $\mathrm{H}_{2} \mathrm{SO}_{4}$ and $\mathrm{NaOH}$ had almost the same effectiveness. However, RS's spectra showed the total opposite where $\mathrm{H}_{2} \mathrm{SO}_{4}$ had only weak peaks, a diffraction peak for $\mathrm{KOH}$ sharper than others, followed by $\mathrm{NaOH}$. The same characteristics were shown where these PACs exist in metallic form. Figure 1(b) revealed that the PAC might contain potassium compounds with high crystallinity after activation with $\mathrm{KOH}$. This finding is similar to that for the tamarind seed-based $\mathrm{AC}^{45}$ and petroleum coked-based $\mathrm{AC}^{46}$ prepared with chemical activation.

Figure 2 shows the spectra of the PAC adsorbents obtained using FTIR. The broad peaks characteristics of the vibration bands around $3851 \mathrm{~cm}^{-1}$ and $3,645 \mathrm{~cm}^{-1}$ corresponded to the $\mathrm{O}-\mathrm{H}$ stretching of hydroxyl groups, while $3481 \mathrm{~cm}^{-1}$ indicated N-H stretching of the alkoxy groups ${ }^{47-49}$. The spectrum at $3300-3500 \mathrm{~cm}^{-1}$ was one of the most detected peaks in activated carbons obtained in previous studies ${ }^{50,51}$. In the PACs FTIR spectrum, the band centered around $2124 \mathrm{~cm}^{-1}$ corresponded to $\mathrm{C}=\mathrm{C}$ stretching vibration and $\mathrm{C}=\mathrm{N}$ bond. The bands around $1968 \mathrm{~cm}^{-1}$ and $1,593 \mathrm{~cm}^{-1}$ indicated $\mathrm{C}=\mathrm{O}$ stretching and $\mathrm{N}-\mathrm{H}$ bending vibrations of the alkoxy groups. The existence of those peaks demonstrated that the synthesized PACs contained abundant functional groups and proved the formation of hydrogen bonding between the functional groups, based on the slight shift of $\mathrm{OH}$, $\mathrm{C}-\mathrm{O}$, and $\mathrm{N}-\mathrm{H}$ functional groups. 
a)

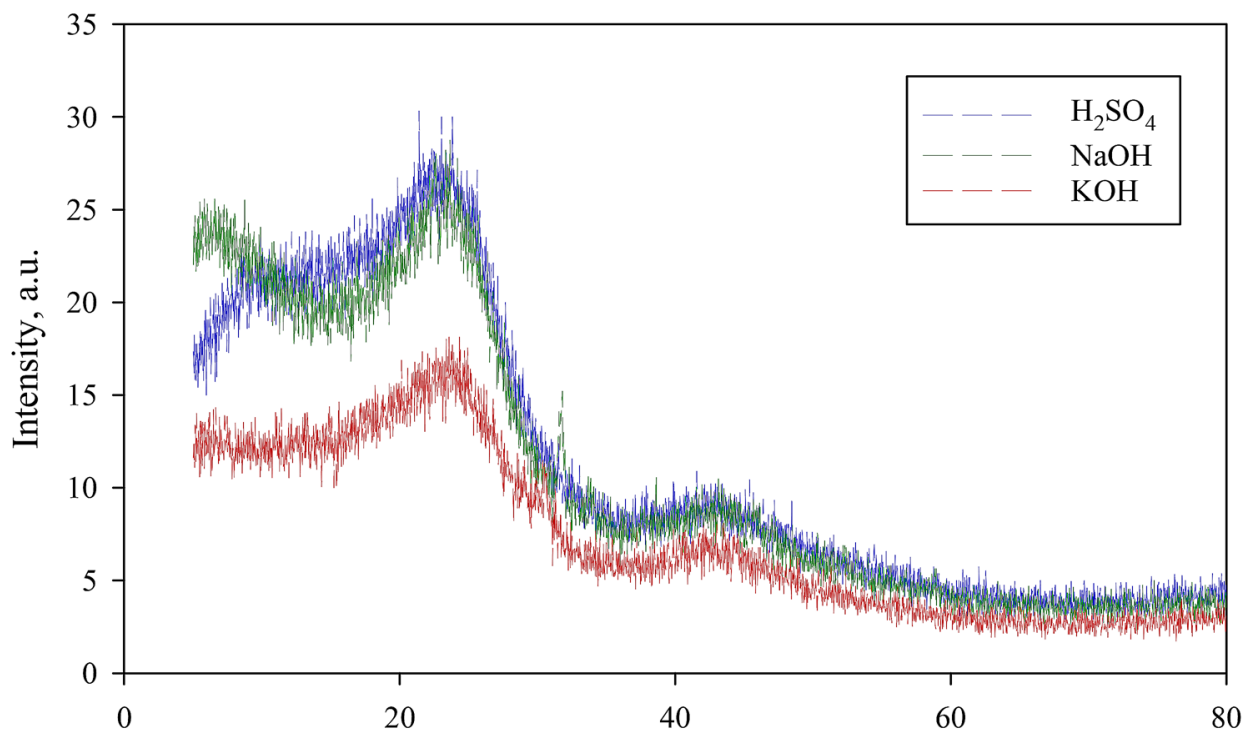

$2 \Theta$, degree

b)

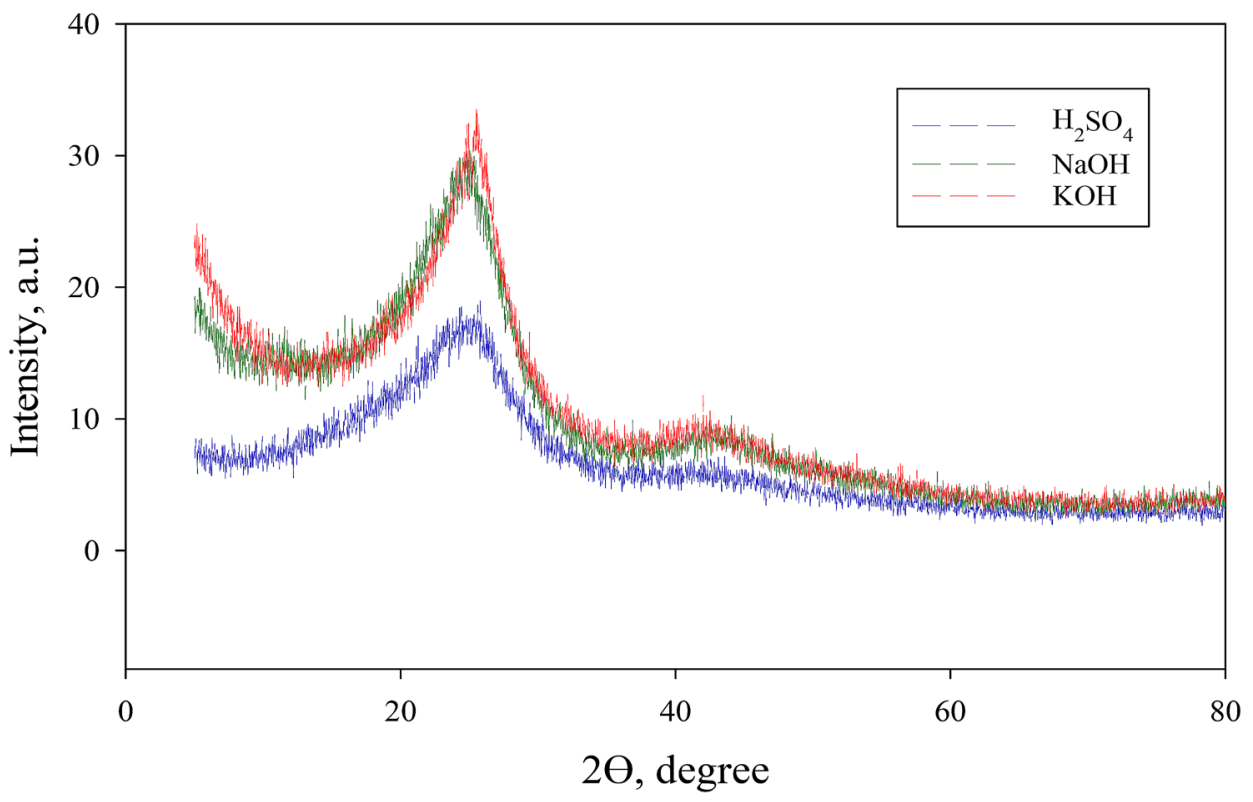

Figure 1. (a) XRD of the PAC from RSS based on activation solutions and (b) XRD of the PAC from RS based on activation solutions.

The cross-sectional morphology of the PACs is shown in Fig. 3a-f. They reveal the presence of a uniformsized porous surface in the composites. The $\mathrm{NaOH}$-activated PACs by RSS and $\mathrm{NaOH}$ by RS had the largest pores compared to the other. Based on the size of its pores and its morphology, the largest pores should be the most effective in the study of dye adsorption. Furthermore, as supported by the FTIR results, the Energy Dispersive $\mathrm{x}$-Ray (EDX) mapping (Fig. 4a-f) showed a uniform distribution of the carbon element and oxygen compound. Figure 5 illustrates the Raman spectra of the PAC. The two extensive peaks in all plots of $1300-1400 \mathrm{~cm}^{-1}$ and $1550-1600 \mathrm{~cm}^{-1}$ refer to the D and G bands, respectively. The D band represents structural imperfections of oxygenated groups in the carbon atoms and a disordered sp 3 carbon structure. In contrast, the G band showed sp2-ordered crystalline graphite-like structures that originated from activated carbons' phonon models $\mathrm{s}^{52}$. The ID/IG ratios indicated the size of the ring clusters in the sp2 and sp3 networks and the degree of oxidation in the PACs, which are close to one in the PAC ${ }^{53-57}$. Thus, the graphitization of the PAC was considered successful.

Zeta potential was also conducted to analyze the magnitude of the charge repulsion/ attraction between particles used to measure the material's stability (Fig. 6). The negative symbol in front of the zeta potential means that the scattering object's net charge (including up to the slipping plane) was negative. MB uptake was high at 


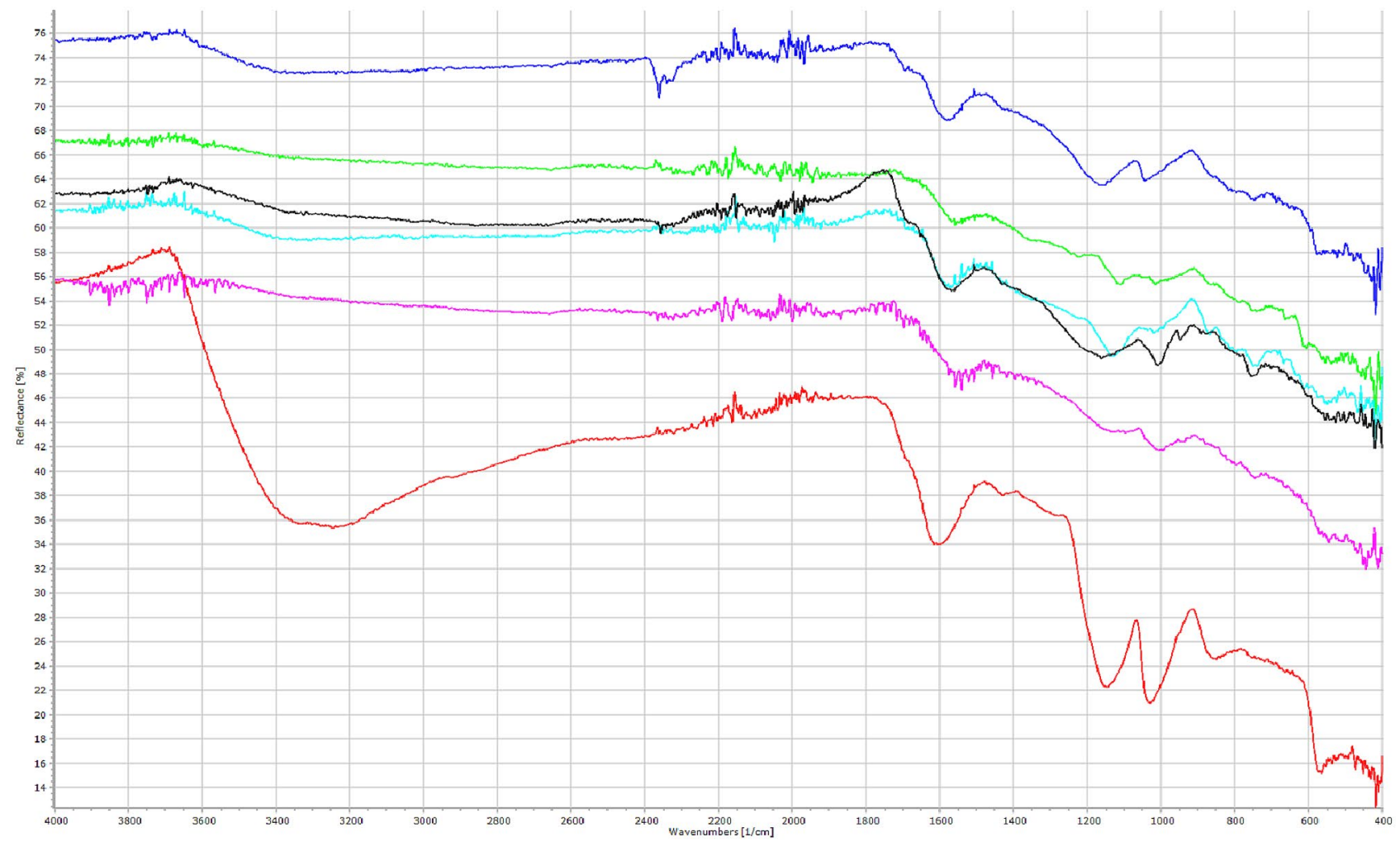

Figure 2. FTIR spectra of PAC adsorbent.
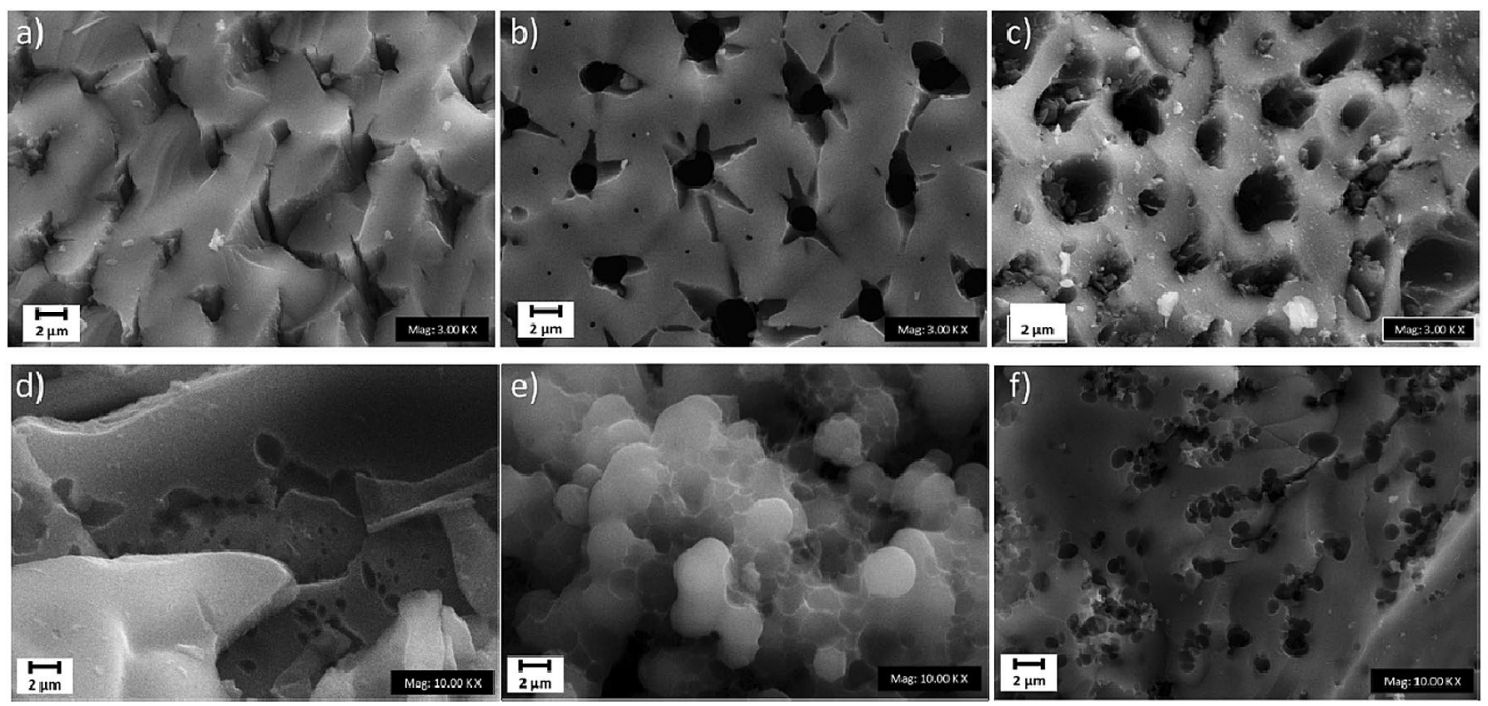

Figure 3. FESEM photographs of the PAC based on activation solutions of (a) $\mathrm{RSS}_{2} \mathrm{SO}_{4}$, (b) RSS KOH, (c) RSS $\mathrm{NaOH}$, (d) $\mathrm{RS} \mathrm{H}_{2} \mathrm{SO}_{4}$, (e) $\mathrm{RS} \mathrm{KOH}$, and (f) $\mathrm{RS} \mathrm{NaOH}$.

alkaline solutions due to the electrostatic attraction between adsorbents and adsorbates' surface. The PAC showed a significant decrease in charge at higher $\mathrm{pH}$ and reached its maximum negative charge at about $\mathrm{pH} 6$ due to the PAC functional groups' protonation. This demonstrated that the negatively charged PAC effectively removed the positively charged $\mathrm{MB}$ at the basic $\mathrm{pH}$. This effectiveness is due to a more negatively charged surface, leading to a higher ionization rate and protonation of the adsorbent's oxygen and hydroxyl groups.

Initial adsorption performance. Figure 7 showed the removal percentage of dyes in the preliminary study. The FESEM supported this finding. EDX mapping results based on the pores' size where the PACs impregnated with $\mathrm{NaOH}$ (RSS) and $\mathrm{H}_{2} \mathrm{SO}_{4}$ (RS) showed the highest percentage removal, therefore were used for the subsequent adsorption study. The existence of large functional groups proved in the FTIR analysis was also the primary reason for the adsorption capability. 

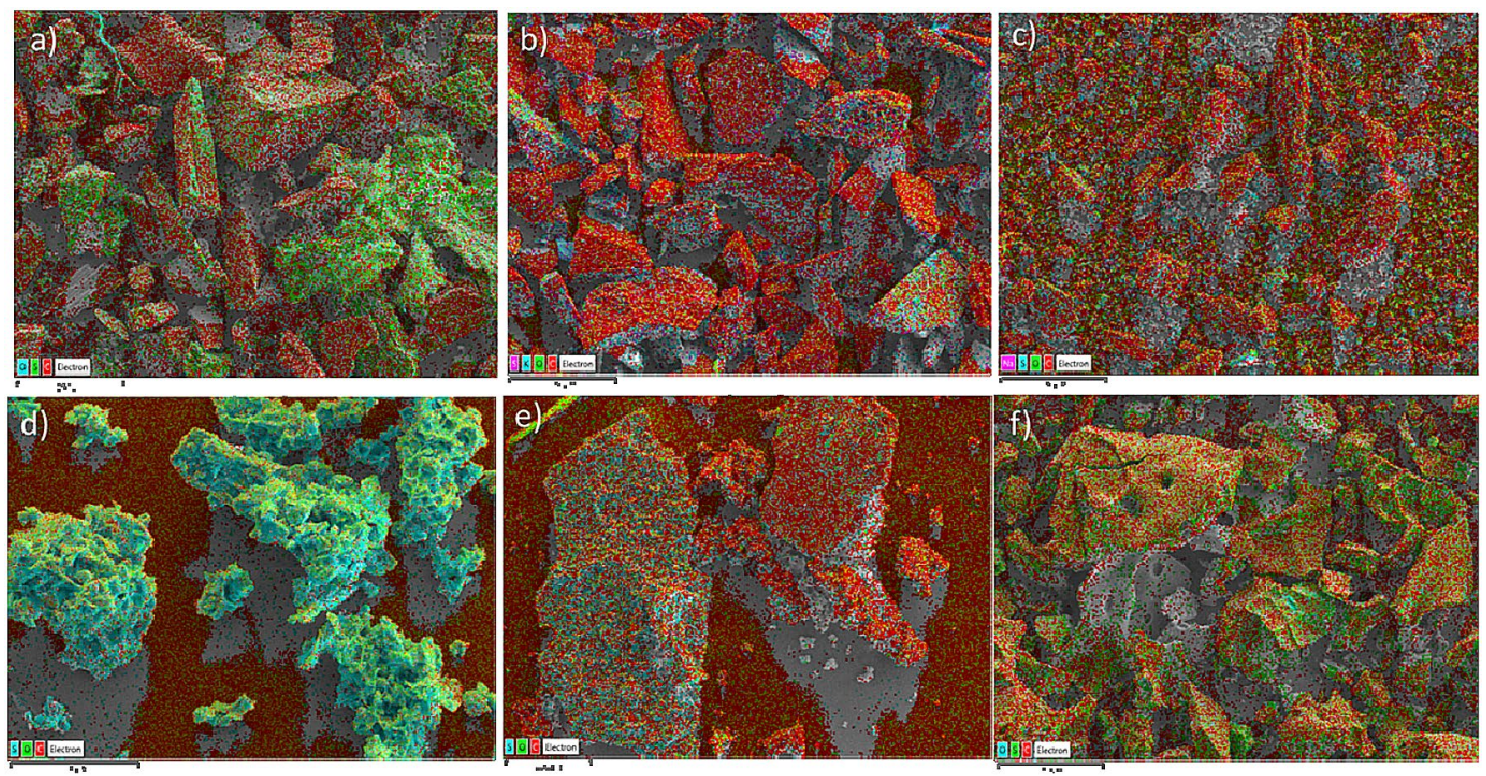

Figure 4. EDX mapping of the PACs based on activation solutions where (a) is $\mathrm{RSS}_{2} \mathrm{SO}_{4}$, (b) is RSS $\mathrm{KOH}$, (c) is $\mathrm{RSS} \mathrm{NaOH}$, (d) is $\mathrm{RS}_{2} \mathrm{SO}_{4},(\mathbf{e})$ is $\mathrm{RS} \mathrm{KOH}$, and (f) is RS NaOH.

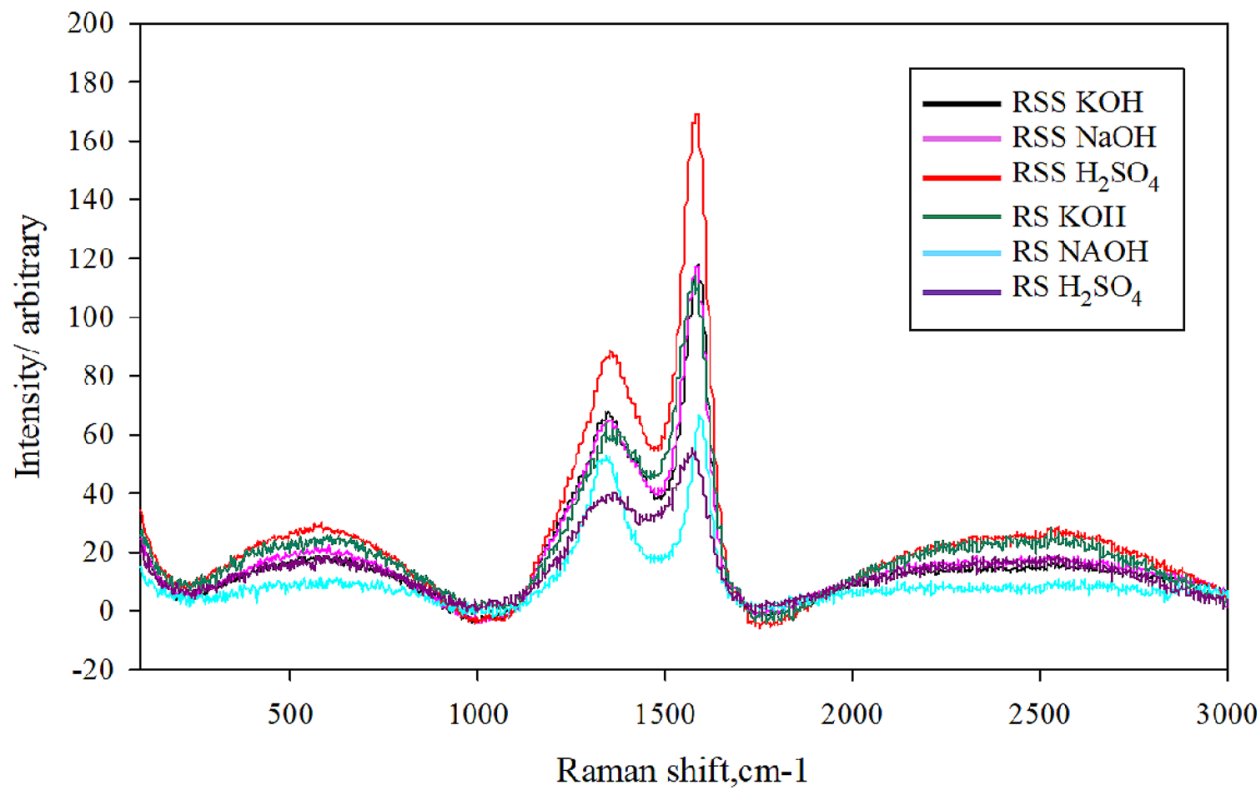

Figure 5. Raman spectroscopy of PAC using various activation solutions.

\section{Adsorption study}

Adsorbent dosage. The study of the adsorbent dosage is essential for avoiding waste of the material once the equilibrium phase has been reached ${ }^{58}$. The results obtained from the adsorbent dosage analysis for removing dyes using the PAC are shown in Fig. 8a. The percentage of MB removal increased from $21 \%$ to $59 \%$ when the PAC dosage increased from $0.01 \mathrm{~g}$ to $0.09 \mathrm{~g}$. Generally, an increase in the adsorbent dosage implies more active sites or surface area for the interaction between the dyes and PAC. The availability increases the percentage of the dyes removed ${ }^{58,59}$. For $\mathrm{CR}$, the adsorbents performed well, even with a low adsorbent dosage, indicating that low CR has enough active sites for the CR to react and adsorb effectively. At the adsorbent dose range of 0.05-0.07, the adsorption efficiency did not change significantly for both dyes, and the resulting graph is flat. This resulted because the number of active sites adsorbent in the aqueous solution for the dye molecules was greater than the number of dye molecules. As a result, several active sites were unutilized ${ }^{31,33}$. Hence, the reduction in adsorption capacity was observed. 


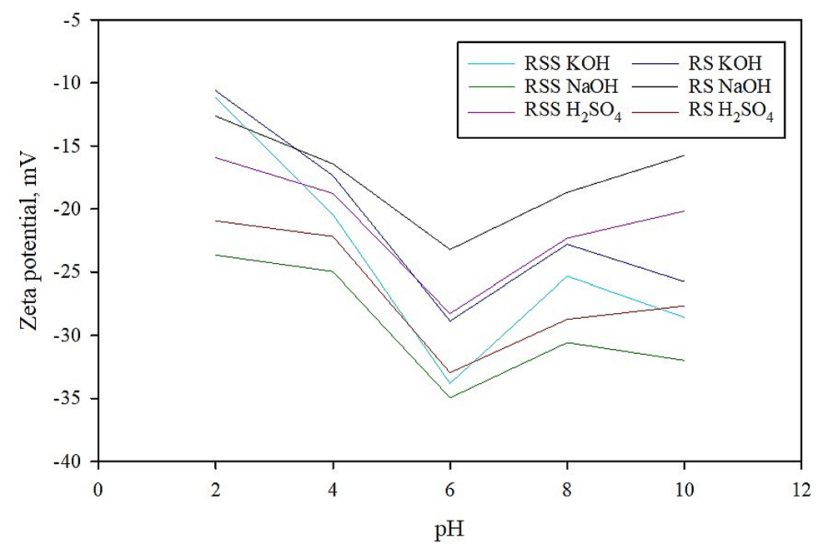

Figure 6. Zeta potential of the PAC adsorbent at various $\mathrm{pH}$ values.

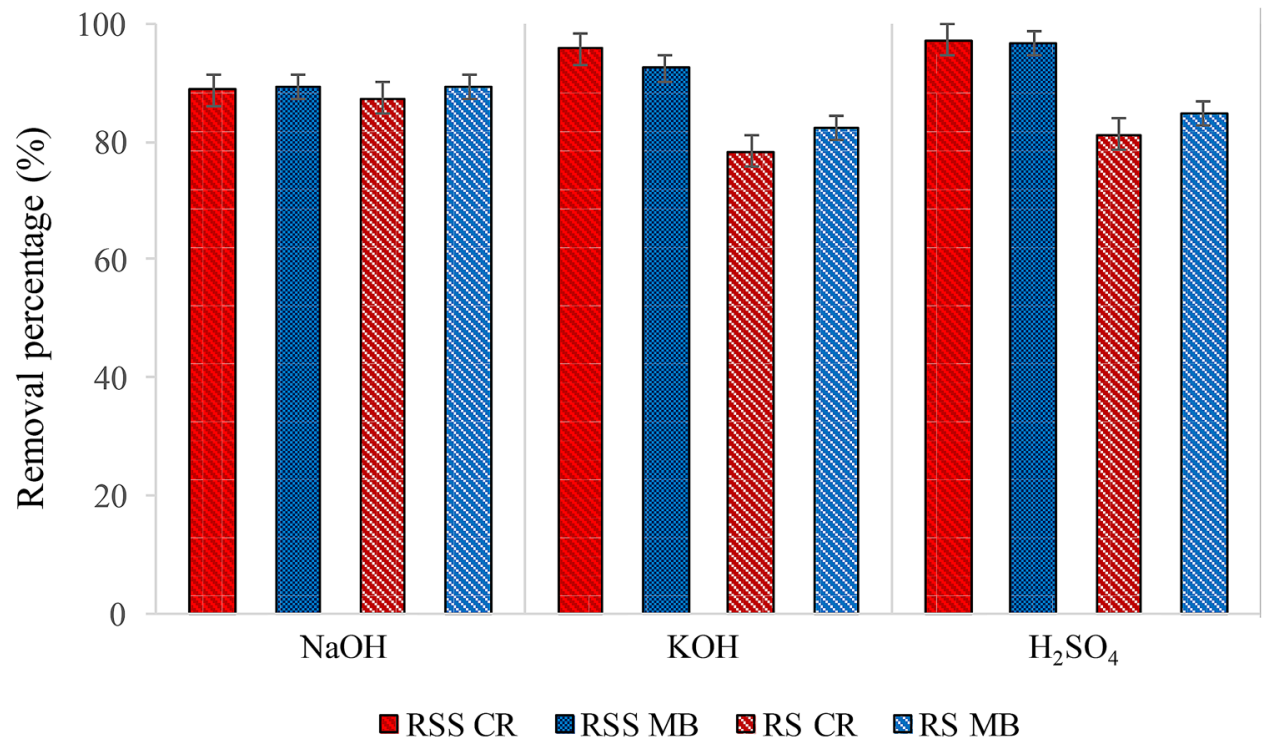

Figure 7. Adsorption removal study using various activating agents for $\mathrm{MB}$ and $\mathrm{CR}$ using PAC.

Contact time. Figure $8 \mathrm{~b}$ shows the effect of contact time on the adsorption of dyes. Figure $8 \mathrm{~b}$ shows that the increase in contact time led to a slight rise in CR's adsorption performance. However, the removal percentage was extremely high, ranging from $98 \%$ to $99 \%$, demonstrating that CR's initial adsorption rate by the PAC (RSS and RS) was extremely fast in removing CR. A large number of active sites of the functional adsorbent groups contributed to higher adsorption rates for CR, nearly $99 \%$ of removal.

As for MB (RSS), the adsorption performance increased over time. In the beginning stage of the adsorption process, the adsorption rates were typically high due to the improved collision of dye molecules in aqueous solutions. When it reached a state of equilibrium in which a reasonable amount of dye was adsorbed, the molecules' collisions were lower due to fewer active sites. At this point, the adsorption rate was slow and constant but steadily increasing.

Dye concentration. Figure $8 \mathrm{c}$ shows the removal percentage for both $\mathrm{CR}$ and $\mathrm{MB}$ decreased as the dye concentration increased. The decline in the uptake percentage of dyes is due to the excessive number of pollutants that exceeded the number of available adsorption sites ${ }^{48,60}$. The PAC showed the best uptake capacity for removing $\mathrm{CR}$ and $\mathrm{MB}$ at concentrations of $40 \mathrm{ppm}$ and $20 \mathrm{ppm}$, respectively, for both RSS and RS. The results showed that the PAC adsorbent possessed a specific number of active sites for the CR and MB dyes' adsorption. This indicated many unused active sites due to the greater number of active sites for the dye molecules' adsorbent than the number of dye molecules. This led to a reduction of adsorption capacity.

Temperature. Another vital parameter that directly impacted the adsorption of dyes was temperature, affecting the solid-solute interface and mobility of pollutants during adsorption ${ }^{61}$. In this study, the efficiency of both MB and CR adsorptions decreased with increasing solution temperature (Fig. 8d). This situation may 


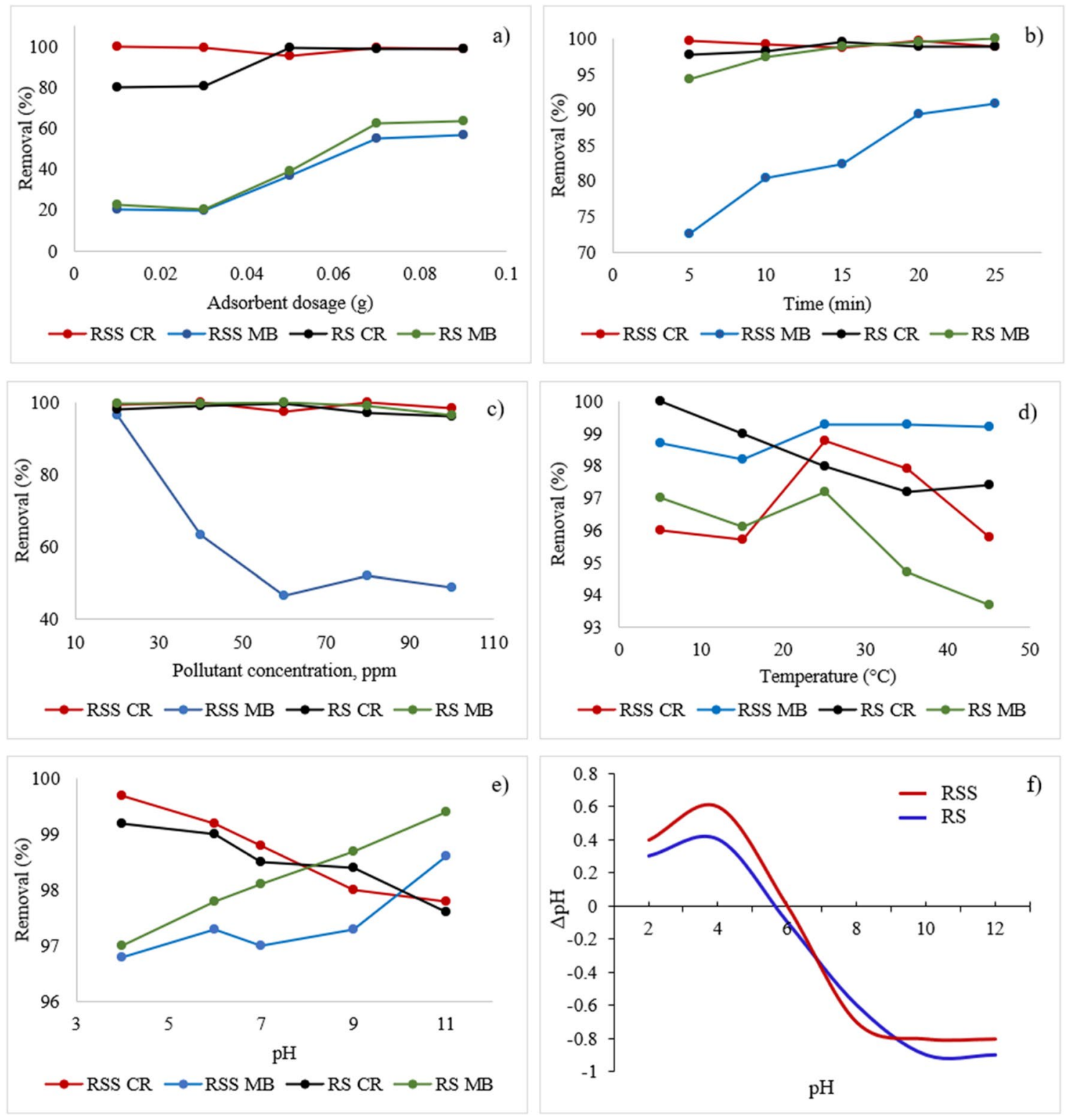

Figure 8. Effect of (a) adsorbent dose, (b) contact time, (c) pollutant concentration, (d) temperature, (e) $\mathrm{pH}$ on the adsorption of dyes by the PAC, and (f) The pHpzc values for RS and RSS.

be due to shrinkage and alteration of active sites on the adsorbent at a higher temperature, reducing the active adsorbent surface, and leaching the dyes into the solution due to a higher separation between the dye molecules and the adsorbent at high temperature ${ }^{31-33}$. This phenomenon demonstrated that both MB and CR's adsorption is an exothermic process that favors low-temperature solutions.

$\mathrm{pH}$. The effect of $\mathrm{pH}$ on dye adsorption affects the interaction between the PAC and the dyes. The $\mathrm{pH}$ of the solution influences the surface charge of the adsorbent and the ionization of the adsorbate. However, hydrophobic interaction, hydrogen bonds, $\pi-\pi$ interaction, and $n-\pi$ interaction also affect the adsorption performance in aqueous solutions ${ }^{58,62,63}$. The effects of $\mathrm{pH}$ are presented in Fig. $8 \mathrm{e}$.

The highest rate of removal of CR was at $\mathrm{pH} 4$, with an uptake of almost $100 \%$. CR is negatively charged and effective when removed by the PACs at $\mathrm{pH}$. The attraction forces between an aqueous solution with low $\mathrm{pH}$ (high value of $\mathrm{H}^{+}$charge) and the negatively charge $\mathrm{CR}$ dye is high, causing the adsorption efficiency to increase $^{31,33}$. Similar results were also reported for the adsorption of CR in several studies ${ }^{1,2,64,65}$. According to Barkauskas et al. ${ }^{66}$ and Debnath et al. ${ }^{61}$, CR uses two mechanisms in the process of adsorption: $\pi-\pi$ interaction between the basal planes of the PAC and aromatic rings of the dyes. Also present are hydrogen bonds between oxygen and the amino groups of CR, oxygen, and the hydroxyl groups of the adsorbent. The condition with the lowest point of the surface charge of the adsorbent $(\mathrm{pH} 4)$ allows the ionization and protonation of the adsorbent's functional groups to reach their maximum rate, contributing to the highest adsorption uptake of CR. The 


\begin{tabular}{|l|l|c|c|c|c|}
\hline \multirow{4}{*}{ Kinetic model } & & \multicolumn{2}{l|}{ CR } & \multicolumn{2}{l|}{ MB } \\
\cline { 2 - 6 } & \multirow{2}{*}{ Parameter } & RSS & \multicolumn{2}{l|}{ RS } & \multicolumn{2}{l|}{ RSS } & \multicolumn{2}{l|}{ RS } \\
\hline \multirow{4}{*}{ Pseudo-first-order } & $\mathrm{R}^{2}$ & 0.89 & 0.95 & 0.98 & 0.98 \\
\cline { 2 - 6 } & $\mathrm{q}_{\mathrm{e}}(\mathrm{mg} / \mathrm{g})$ & 19.47 & 1.97 & 19.86 & 11.55 \\
\cline { 2 - 6 } & $\mathrm{k}_{1}\left(\mathrm{~min}^{-1}\right)$ & 0.03 & 0.35 & 0.05 & 0.45 \\
\hline \multirow{4}{*}{ Pseudo-second order } & $\mathrm{R}^{2}$ & 0.99 & 1.00 & 1.00 & 1.00 \\
\cline { 2 - 6 } & $\mathrm{q}_{\mathrm{e}}(\mathrm{mg} / \mathrm{g})$ & 24.65 & 21.93 & 25.43 & 20.65 \\
\cline { 2 - 6 } & $\mathrm{k}_{2}\left(\mathrm{~g} \mathrm{mg}^{-1} \mathrm{~min}^{-1}\right)$ & 0.02 & 0.2212 & 0.03 & 0.1755 \\
\hline \multirow{4}{*}{ Elovich } & $\mathrm{K}_{\mathrm{ID}}$ & 1.42 & 0.81 & 1.64 & 0.78 \\
\cline { 2 - 6 } & $\mathrm{C}$ & 1.87 & 2.77 & 1.54 & 2.39 \\
\cline { 2 - 6 } & $\mathrm{R}^{2}$ & 0.91 & 0.96 & 0.89 & 0.88 \\
\hline & $\alpha(\mathrm{mg} / \mathrm{g} \cdot \mathrm{min})$ & 1.96 & 1.07 & 1.48 & 0.63 \\
\cline { 2 - 6 } & $\beta(\mathrm{g} / \mathrm{mg})$ & 0.73 & 2.89 & 0.51 & 11.84 \\
\cline { 2 - 6 } & $\mathrm{R}^{2}$ & 0.85 & 0.73 & 0.81 & 0.94 \\
\hline
\end{tabular}

Table 1. The correlation coefficient, $\mathrm{R}^{2}$ of pseudo-first and pseudo-second orders of RS and RSS.

\begin{tabular}{|l|l|r|r|r|r|}
\hline \multirow{4}{*}{ Models } & & \multicolumn{2}{l|}{ CR } & \multicolumn{2}{l|}{ MB } \\
\cline { 2 - 6 } & Parameter & RSS & \multicolumn{1}{l|}{ RS } & \multicolumn{1}{l|}{ RSS } & \multicolumn{1}{l|}{ RS } \\
\hline \multirow{4}{*}{ Freundlich } & $\mathrm{k}\left(\mathrm{mg} \mathrm{g}^{-1}\right)$ & 0.57 & 0.32 & 0.48 & 0.28 \\
\cline { 2 - 6 } & $1 / \mathrm{n}$ & 0.46 & 0.53 & 2.14 & 0.18 \\
\cline { 2 - 6 } & $\mathrm{R}^{2}$ & 0.89 & 0.67 & 0.76 & 0.91 \\
\hline \multirow{4}{*}{ Langmuir } & $\mathrm{R}^{1}$ & 0.99 & 0.79 & 0.79 & 0.51 \\
\cline { 2 - 6 } & $\mathrm{Q}_{\max }\left(\mathrm{mg} \mathrm{g}^{-1}\right)$ & 659.35 & 227.27 & 458.43 & 769.23 \\
\cline { 2 - 6 } & $\mathrm{R}^{2}$ & 0.98 & 0.51 & 0.64 & 0.87 \\
\hline \multirow{3}{*}{ Dubinin-Radushkevich } & $\mathrm{Q}_{\max }\left(\mathrm{mg} \mathrm{g}^{-1}\right)$ & 471.77 & 93.61 & 479.81 & 63.37 \\
\cline { 2 - 6 } & $\mathrm{E}\left(\mathrm{kJ} / \mathrm{mol}^{\prime}\right)$ & 1.65 & 2.34 & 1.84 & 2.67 \\
\cline { 2 - 6 } & $\mathrm{R}^{2}$ & 0.81 & 0.76 & 0.67 & 0.54 \\
\hline
\end{tabular}

Table 2. Parameter values of the isotherm models in the adsorption of dyes by the PAC adsorbent.

MB dye showed excellent adsorption in a basic medium, as expected due to its cationic properties. As the $\mathrm{pH}$ increased, the $\mathrm{H}+$ charges in the solution decreased, resulting in less competition between positive ions and dye molecules. Because the PAC was negatively charged at high $\mathrm{pH}$, an increase in the electrostatic force of gravity between the surface of the adsorbent and cationic dye molecule exists, leading to increasing adsorption efficiency. The pHpzc values for RS and RSS were 5.6 and 6.0, respectively (Fig. 8f). This indicated that when $\mathrm{pH}<\mathrm{pHpzc}$, the adsorbent surface is positively charged and tends to absorb anionic species or negatively charged dye, which in this case is $\mathrm{CR}$, while cationic species (MB) tends to absorb on the surface of negatively charged adsorbents $(\mathrm{pH}>\mathrm{pHpzc})$ due to electrostatic interactions ${ }^{31}$.

Adsorption kinetics. As shown in Table 1, the correlation coefficient of determination $\left(\mathrm{R}^{2}\right)$ of the pseudosecond-order kinetic model exceeded 0.99 (RSS and RS), significantly higher than those of the pseudo-firstorder kinetic model. This finding indicated that a chemical effect was involved in the adsorption of dyes on PAC. Moreover, the calculated values of the equilibrium adsorption capacity $\left(q_{e}\right)$ from the pseudo-second-order showed an absolute agreement with the experimental values $\left(\mathrm{q}_{\mathrm{e}, \text { exp }}\right)$. These results further indicated that the pseudo-second-order model was more suitable for the adsorption of dye onto the PAC, showing that the adsorption was chemically controlled. In addition, the lower correlation coefficient values in the pseudo-first-order and the Elovich model showed that these models did not agree on how to explain the adsorption mechanism, suggesting that the process was indeed efficient and controlled by chemical adsorption, as mentioned earlier ${ }^{67-72}$. This process involved the exchange of electrons between the adsorbates and adsorbent ${ }^{31,47,73-76}$. The $\alpha$ parameter values using Elovich kinetic model for RSS for both dyes were higher than RS, indicating that RSS had a greater tendency and ability to adsorb dyes. The experimental results also supported these findings. The values for the intraparticle diffusion rate constant $\left(\mathrm{K}_{\mathrm{ID}}\right)$ for RSS in the adsorption process of both dyes was higher than RS, also indicating that RSS had better adsorption and more improved bonding between the adsorbent and adsorbate particles $^{31-34,68,70-72}$.

Adsorption isotherms. Isotherm models of Langmuir, Freundlich, and Dubinin-Radushkevich were fitted to the experimental data; the parameters obtained for these equations are tabulated in Table 2. According to the values of $\mathrm{R}^{2}$ and other parameters in Table 2, the fittings of Langmuir, Freundlich, and Dubinin- Radushk- 


\begin{tabular}{|c|c|c|c|c|c|c|c|}
\hline \multirow[b]{2}{*}{ Sample } & \multirow[b]{2}{*}{ Temperature $\left(\mathbf{K}^{\circ}\right)$} & \multicolumn{2}{|c|}{$\Delta \mathbf{H}\left(\mathrm{kJ} \mathrm{mol}^{-1}\right)$} & \multicolumn{2}{|c|}{$\Delta S\left(\mathrm{~kJ} \mathrm{~mol}^{-1}\right)$} & \multicolumn{2}{|c|}{$\Delta \mathrm{G}\left(\mathrm{kJ} \mathrm{mol}^{-1}\right)$} \\
\hline & & CR & MB & CR & MB & CR & MB \\
\hline \multirow{4}{*}{ RSS } & 298 & -0.099 & -1.158 & -0.017 & -0.063 & -0.094 & -1.131 \\
\hline & 303 & & & & & -0.093 & -1.129 \\
\hline & 313 & & & & & -0.091 & -1.122 \\
\hline & 323 & & & & & -0.090 & -1.117 \\
\hline \multirow{4}{*}{ RS } & 298 & -0.097 & -1.135 & -0.042 & -0.008 & -0.092 & -1.119 \\
\hline & 303 & & & & & -0.091 & -1.116 \\
\hline & 313 & & & & & -0.089 & -1.115 \\
\hline & 323 & & & & & -0.088 & -1.111 \\
\hline
\end{tabular}

Table 3. Thermodynamic parameters in the adsorption of $\mathrm{MB}$ and $\mathrm{CR}$ by the PAC adsorbent.

evich models showed the degree of surface saturation by using isotherm models. The values of $E$ for the PACs adsorption process were $1.65 \mathrm{~kJ} / \mathrm{mol}$ (RSS) and $2.34 \mathrm{~kJ} / \mathrm{mol}$ (RS) for CR dye and $1.84 \mathrm{~kJ} / \mathrm{mol}$ (RSS) and $2.67 \mathrm{~kJ} /$ $\mathrm{mol}$ (RS) for $\mathrm{MB}$, demonstrating that the adsorption process of both dyes was desirable and physical ${ }^{31}$. Adsorption of CR by PAC was well-fitted with the Langmuir isotherm. This verifies that the adsorption occurred in a monolayer manner ${ }^{68-72}$ because the PACs' large surface area influenced the adsorption of large CR molecules onto the PACs ${ }^{48}$. The value of $\mathrm{R}^{2}$ determines the models' suitability, and the $\mathrm{Q}_{\max }$ value was calculated to be considerably high, as shown in Table 2. On the other hand, the Freundlich model was determined to be suitable to explain the adsorption of $\mathrm{MB}$, considered the amount of $\mathrm{CR}$ adsorbed per unit mass of PACs used. According to these results, the PAC's adsorption of the dyes occurred mainly in monolayer and multilayer manners. The monolayer adsorption was determined by the Langmuir model, while the Freundlich model showed the adsorption of the dyes on the surface of the adsorbent in multilayers. The presence of functional groups of PACs which contributed to $\pi-\pi$ interaction and electrostatic interaction between the adsorbents and adsorbates explained the adsorption mechanism ${ }^{31,48,74-78}$.

Thermodynamics study. A positive $\Delta G$ generally showed that an external source of energy is required during the adsorption process. Meanwhile, a negative $\Delta \mathrm{G}$ factor indicated the feasibility of the adsorption process and its spontaneous nature without the need for an external energy source. The negative $\Delta \mathrm{G}$ values obtained in this study (Table 3 ) showed that the adsorption process that removed MB and CR occurred spontaneously without the need for an external energy source. In addition, the $\Delta \mathrm{G}$ values for CR were lower than $-1 \mathrm{~kJ} \mathrm{~mol}^{-1}$ at various temperatures, which showed that physical adsorption is an effective mechanism in this process ${ }^{47,67}$. In this study, the values of $\Delta \mathrm{H}$ for the $\mathrm{CR}$ and MB were $-0.099 \mathrm{~kJ} \mathrm{~mol}^{-1}$ and $-1.158 \mathrm{~kJ} \mathrm{~mol}^{-1}$, respectively, confirming the adsorption process was exothermic ${ }^{31,33}$. The negative value in both $\mathrm{MB}$ and $\mathrm{CR}$ for $\triangle \mathrm{S}$ was ascribed to the fact that the adsorbates lose randomness in the solid-solute interface during the adsorption process ${ }^{47,58,79-81}$. However, the $\Delta G$ values' temperature was not significant within the range of temperatures investigated. The results of this analysis clearly showed that the adsorption of both MB and CR were exothermic and spontaneous. The process contributed to reduced adsorption capability as temperature increased (Fig. 8e).

Effects of ionic strength, PAC regeneration, and comparison with other adsorbents. The effects of ionic strength in an aqueous solution were studied using a $\mathrm{NaCl}$ solution $(0.01-0.3 \mathrm{~mol} / \mathrm{L})$ as the electrolyte solution to examine the adsorption process's efficiency on RS and RSS activated carbon. The results are shown in Fig. 9a. At a higher concentration of the electrolyte solution, the dye removal efficiency using RS and RSS activated carbon decreased. This activation was due to the competition between the $\mathrm{Na}^{+}$and PAC molecules. At a higher $\mathrm{NaCl}$ solution concentration, the negatively charged functional groups $\left(\mathrm{OH}^{-}, \mathrm{COO}^{-}\right)$interacted electrostatically with $\mathrm{Na}^{+}$ions ${ }^{33}$. The same charges on the adsorbent surface between the two created a repulsive electrostatic force, causing the adsorption process's efficiency to decrease.

In this study, the regeneration was accomplished through ten cycles. PAC adsorbents were washed with $\mathrm{HCl}$ in between cycles, and the results are presented in Fig. 9b. The adsorption percentage was reduced to only $1 \%$ after six times recycling the adsorbent in CR removal, and there was no decline was observed in $\mathrm{MB}$ removal. However, the change in removal efficiency was seen in the seventh cycle, with a $3 \%$ decline in the CR and a $2 \%$ decline for MB removal performance. The adsorbents' excellent life cycle and regeneration ability could be correlated to the pretreatment methods and high porosity of the synthesized adsorbent.

Table 4 shows the data from previous studies using different types of biomass-based adsorbents. By comparison, adsorption of MB and CR using PAC derived from RSS and RS showed encouraging results compared to other adsorbents previously used. The highest value reported was $612.1 \mathrm{mg} \mathrm{g}^{-1}$ of MB removed using activated carbon derived from date palm seeds ${ }^{76}$. In this study, the highest adsorption capacity was $769.23 \mathrm{mg} \mathrm{g}^{-1}$ for $\mathrm{MB}$ using rubber seeds, while CR was $458.43 \mathrm{mg} \mathrm{g}^{-1}$. Therefore, rubber seeds appeared to be the most effective in removing $\mathrm{MB}$, while the shells are the best option to remove $\mathrm{CR}$. Due to the synergistic effect of various functional groups, biomass-derived PACs demonstrated the superior adsorption capability for MB and CR. 

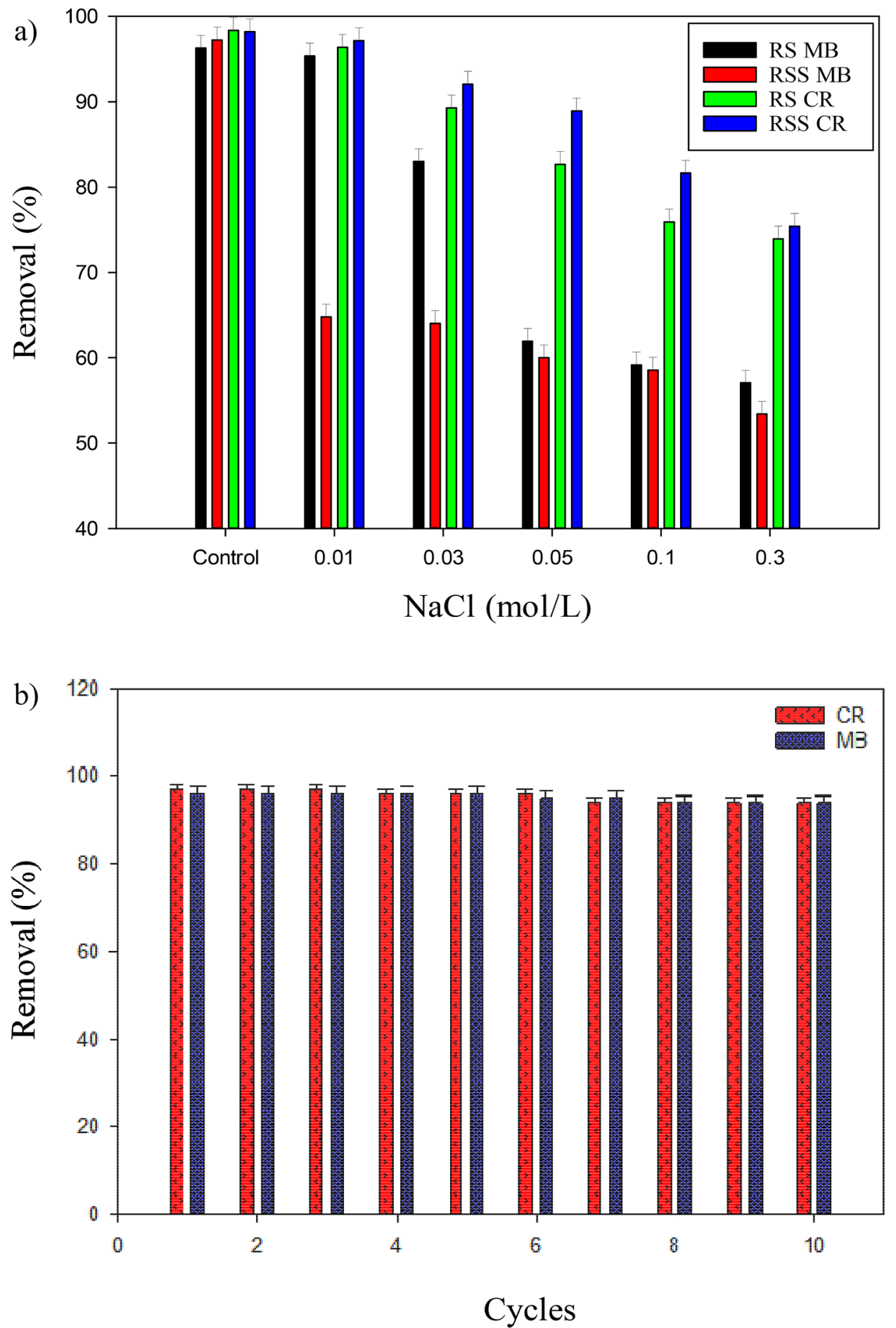

Figure 9. (a) Influence of the solution ionic strength on dyes adsorption capacity; and (b) Regeneration ability of PAC for removing $\mathrm{MB}$ and $\mathrm{CR}$ dyes.

\section{Conclusions}

In this study, PAC adsorbents from RS and RSS were successfully synthesized. The results of FESEM and EDX mapping showed a porous surface in uniform sizes, with $\mathrm{PAC}$ activated by $\mathrm{NaOH}$ (RSS) and $\mathrm{H}_{2} \mathrm{SO}_{4}$ (RS) having the largest pores. The prepared adsorbent showed excellent CR and MB adsorptions. The affinity for adsorption by the PACs was due to its single-layered planes with the functional groups (hydroxyl, alkoxy, and carboxyl), as reported in FTIR analysis. The $\pi-\pi$ interactions and hydrogen bonds of the PACs with CR and MB enhanced the adsorbent performance. Based on multiple studies, the PACs activated by $\mathrm{NaOH}$ were more effective than the other two impregnation agents $\left(\mathrm{NaOH}\right.$ and $\mathrm{H}_{2} \mathrm{SO}_{4}$ ) for RSS, and $\mathrm{H}_{2} \mathrm{SO}_{4}$ was found to be the best for RS. 


\begin{tabular}{|c|c|c|c|}
\hline Adsorbent & Adsorbate & $\mathrm{Q}_{\max }\left(\mathrm{mg} \mathrm{g}^{-1}\right)$ & Reference \\
\hline Methylene blue & Date stones & 381.79 & Ahmed and Theydan ${ }^{40}$ \\
\hline Methylene blue & Oil palm fibers & 382.32 & Foo and Hameed ${ }^{41}$ \\
\hline Methylene blue & Coconut husks & 418.15 & Foo and Hameed ${ }^{42}$ \\
\hline Methylene blue & Durian shells & 410.85 & Foo and Hameed ${ }^{43}$ \\
\hline Methylene blue & Date pits & 244.00 & Ashour $^{81}$ \\
\hline Methylene blue & Date pits & 345.00 & Reddy et al. ${ }^{82}$ \\
\hline Methylene blue & Date stones & 316.11 & Foo and Hameed ${ }^{83}$ \\
\hline Methylene blue & Date palm seeds & 612.10 & Islam et al. ${ }^{84}$ \\
\hline Methylene blue & Date pits & 455.00 & Mahmoudi et al. ${ }^{85}$ \\
\hline Methylene blue & Date palm rachis & 198.80 & Daoud et al. ${ }^{86}$ \\
\hline Methylene blue & Microalgal biomass & 113.00 & Yu et al. ${ }^{87}$ \\
\hline Methylene blue & Coconut shell & 156.25 & Yağmur et al. ${ }^{88}$ \\
\hline Methylene blue & N. diderrichii & 35.09 & Omorogie et al. ${ }^{89}$ \\
\hline Methylene blue & Banana roots & 165.00 & Paluri et al. ${ }^{90}$ \\
\hline Methylene blue & Ackee apple pods & 47.17 & Bello et al. ${ }^{91}$ \\
\hline Methylene blue & Soya wastes & 90.00 & Batool and Valiyaveettil ${ }^{92}$ \\
\hline Methylene blue & Corncob wastes & 636.94 & Zhou et al. ${ }^{93}$ \\
\hline Congo red & Watermelon rind & 17.00 & Masoudian et al. ${ }^{2}$ \\
\hline Congo red & Bael shells & 98.03 & Ahmad and Kumar ${ }^{63}$ \\
\hline Congo red & Grape wastes & 455.00 & Sayğılı and Güzel ${ }^{64}$ \\
\hline Congo red & Microalgal biomass & 164.35 & Yu et al. ${ }^{87}$ \\
\hline Congo red & Speargrass leaves & 313.00 & Bello and Banjo ${ }^{94}$ \\
\hline Congo red & Date pits & 105.00 & Belhachemi and Addoun ${ }^{95}$ \\
\hline Congo red & Peanut shells & 150.00 & Lawal et al. ${ }^{96}$ \\
\hline Congo red & Coffee wastes & 90.90 & Lafi et al. ${ }^{97}$ \\
\hline Congo red & Wood wastes & 8.00 & Stjepanovic et al. ${ }^{98}$ \\
\hline Congo red & Rubber seed shells & 458.43 & Present study \\
\hline Methylene blue & Rubber seed shells & 659.35 & Present study \\
\hline Congo red & Rubber seeds & 227.27 & Present study \\
\hline Methylene blue & Rubber seeds & 769.23 & Present study \\
\hline
\end{tabular}

Table 4. Dye adsorption capacities of the resulting activated carbons as reported in the literature.

The maximum adsorption capacities of the PACs were $458.43 \mathrm{mg} \mathrm{g}^{-1}$ (CR by RSS), $659.35 \mathrm{mg} \mathrm{g}^{-1}$ (MB by RSS), $227.27 \mathrm{mg} \mathrm{g}^{-1}$ (CR by RS), $769.23 \mathrm{mg} \mathrm{g}^{-1}$ (MB by RS). The kinetic and isothermal data were well-suited to the pseudo-second-order kinetic model. Based on the isotherm models, more than one mechanism was involved in the adsorption process, a monolayer for the anionic dye and a multilayer for the cationic dye.

A thermodynamic study showed that both dyes' adsorption process was spontaneous and exothermic due to the negative values of the enthalpy $(\Delta \mathrm{H})$ and Gibbs free energy $(\Delta \mathrm{G})$. An acidic $\mathrm{pH}$ range and lower temperature of the solution were unfavorable. At a higher concentration of the electrolyte solution $(\mathrm{NaCl})$, the dye adsorption efficiency using RS and RSS activated carbon decreased due to the competition between the $\mathrm{Na}^{+}$and PAC molecules. Lastly, the adsorbents' superior life cycle and regeneration ability with only a 3\% decline for CR and a $2 \%$ decline for MB could be correlated to the pretreatment methods and high porosity of the synthesized adsorbent.

In this study, the RSS-derived PACs were the most suitable for removing CR dyes, and RS-derived PACs were the best option to remove MB dyes. The results demonstrated that the PAC is a promising adsorbent for purifying and treating dyes in discharged wastewater, particularly in the industrial sector. Analysis and experiments on the effectiveness of other local biomass wastes and the potential for the upscaling of the synthesized PACs into increased production should be explored to solve real-world water quality challenges. In addition, the total energy required to scale up from laboratory tests to a full-scale commercial production plant is worth further investigation to produce environmentally sound technologies for wastewater treatment.

\section{Methods}

Materials. All chemicals used in this study were analytical grade. Potassium hydroxide (KOH), sodium hydroxide $(\mathrm{NaOH})$, sulfuric acid $\left(\mathrm{H}_{2} \mathrm{SO}_{4}\right)$, and hydrochloric acid $(\mathrm{HCl})$ were obtained from Acco Lab Supplies, Malaysia. The MB and CR dyes were purchased from Sigma-Aldrich, Malaysia.

Preparation of PAC. The RS and RSS were washed thoroughly to remove any dirt and impurities and then dried overnight in an oven at $105^{\circ} \mathrm{C}$. Acids and base solutions, $0.5 \mathrm{M} \mathrm{KOH}, 1.5 \mathrm{M} \mathrm{NaOH}$, and $1.5 \mathrm{M} \mathrm{H}_{2} \mathrm{SO}_{4}$, were prepared. The dried sample was cooled at room temperature before proceeding to the next step. The sample was then impregnated with prepared solutions of three different concentrations for six hours. One beaker of dried 


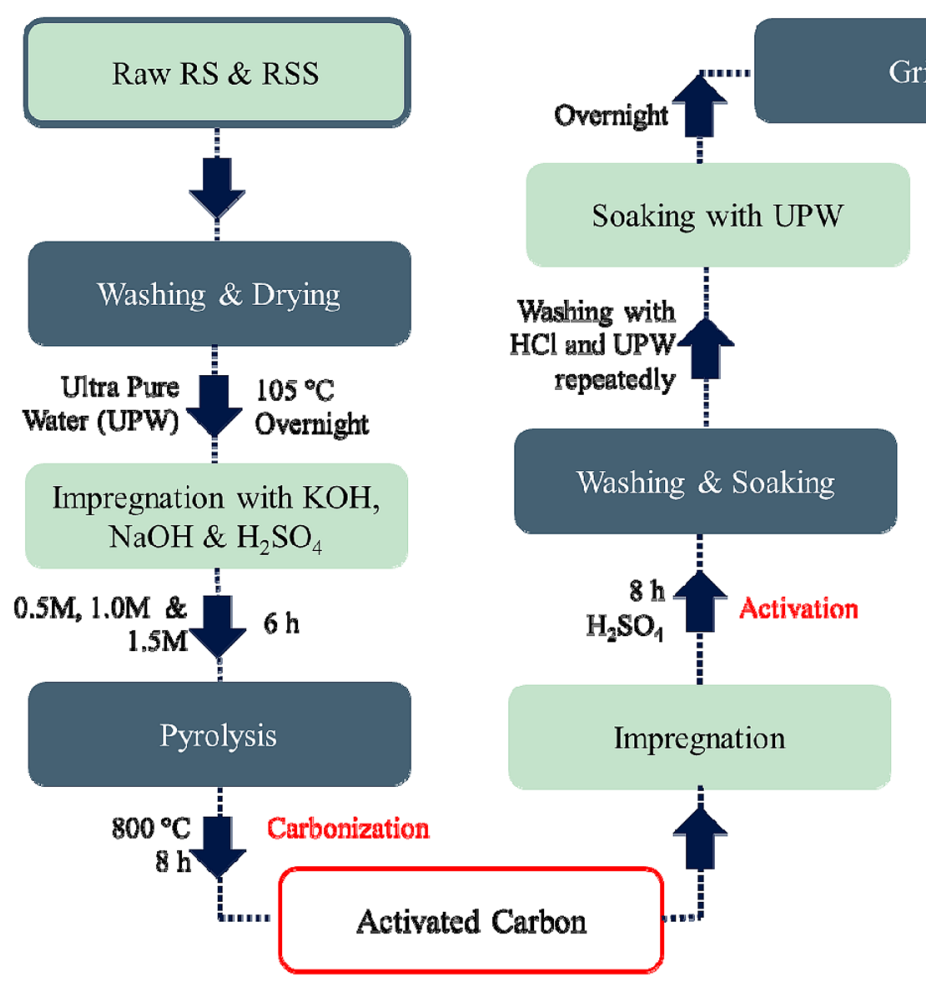

Figure 10. Process for fabrication and synthesis of PAC from RS and RSS.

RSS was soaked with ultra-pure water to be kept as control. After six hours, the impregnated sample was pyrolyzed and gradually carbonized in a furnace for eight hours at $800^{\circ} \mathrm{C}$. The pyrolyzed sample was then cooled at room temperature and soaked with $\mathrm{H}_{2} \mathrm{SO}_{4}$ for eight hours to be activated. The sample was then washed repeatedly with $0.1 \mathrm{M}$ hydrochloric acid $(\mathrm{HCl})$ and ultra-pure water until no color or residual substances remained. For further washing, the sample was soaked with ultra-pure water overnight to ensure it was clear of any impurities, acids, or bases. The processes of preparing and synthesizing the RS and RSS into the PAC are shown in Fig. 10.

Characterization. An FTIR analysis was conducted using a Nicolet 6700 Thermo Scientific-FTIR 12 spectrometer (United States). The purpose was to identify the exterior functional groups and chemical bonds of the synthesized PAC. XRD using a Bruker AXS D8 Advance Karlsruhe (Germany) and XRD DIFFRAC EVA software were used to examine the adsorbent structure, composition, and material properties. Morphological surface mapping of the PAC adsorbent was conducted using a Gemini model 18 SUPRA 55VP-ZEISS Oberkochen (Germany) FESEM equipped with energy-dispersive X-ray 19 spectroscopy (EDX). Zeta potential analysis was used to determine the PAC's surface charge in a colloidal solution using a Zeta Sizer (Nano-ZS, Malvern 17 Instruments Inc. UK). Raman imaging spectroscopy analysis was also conducted (Thermo Scientific I Model: DXR2xi) to analyze the PAC's chemical structure, crystallinity, phase, and polymorphic and molecular interactions based on the interaction of light within the adsorbent. The $\mathrm{pHpzc}$ ( $\mathrm{pH}$ of point zero charge) was also measured to determine the electrostatic nature of the adsorbent's surface.

Adsorption study. The effect of adsorbent dosage, pollutant concentration, solution $\mathrm{pH}$, contact time, and temperature was measured and compared with the accuracy of three replicates. The flow and adsorption parameters are shown in Table 5. For the initial adsorption, $10 \mathrm{ml}$ of synthetic $\mathrm{CR}$ and $\mathrm{MB}$ solutions were used with different impregnation mediums $\left(\mathrm{KOH}, \mathrm{NaOH}\right.$, and $\left.\mathrm{H}_{2} \mathrm{SO}_{4}\right)$ of the $\mathrm{PAC}$ adsorbent. Equal amounts of adsorbent, $0.01 \mathrm{~g}$, were added, and the contact time of the adsorption process was set at two minutes under room temperature. The impregnated PAC's best removal efficiency was identified based on the synthetic solutions' concentration, labeled A, and used in all of the experiments that followed. The following experiments were conducted again but with different adsorbent dosages ranging from $0.02 \mathrm{~g}$ to $0.08 \mathrm{~g}$. Concentrations of synthetic solutions recorded as efficient for removal were labeled $\mathrm{B}$ and used in the following steps. The next steps were repeated with different contact times, pollutant concentrations, solution $\mathrm{pH}$, and temperature and labeled $\mathrm{C}, \mathrm{D}, \mathrm{E}$, and $\mathrm{F}$, consecutively (Table 5). The solution's $\mathrm{pH}$ was regulated to the desired values using $\mathrm{NaOH}$ and $\mathrm{HCl}$ solution (0.1M, pH: 2-10).

The removal percentages of $\mathrm{CR}$ and $\mathrm{MB}$ by the PAC adsorbents were calculated. The solutions' concentration was determined using a UV DR 3900 (HACH, USA) at wavelengths of $496 \mathrm{~nm}$ for CR and $668 \mathrm{~nm}$ for MB. The uptake capacities of the adsorbates by the PAC adsorbent were calculated using Eq. (1): 


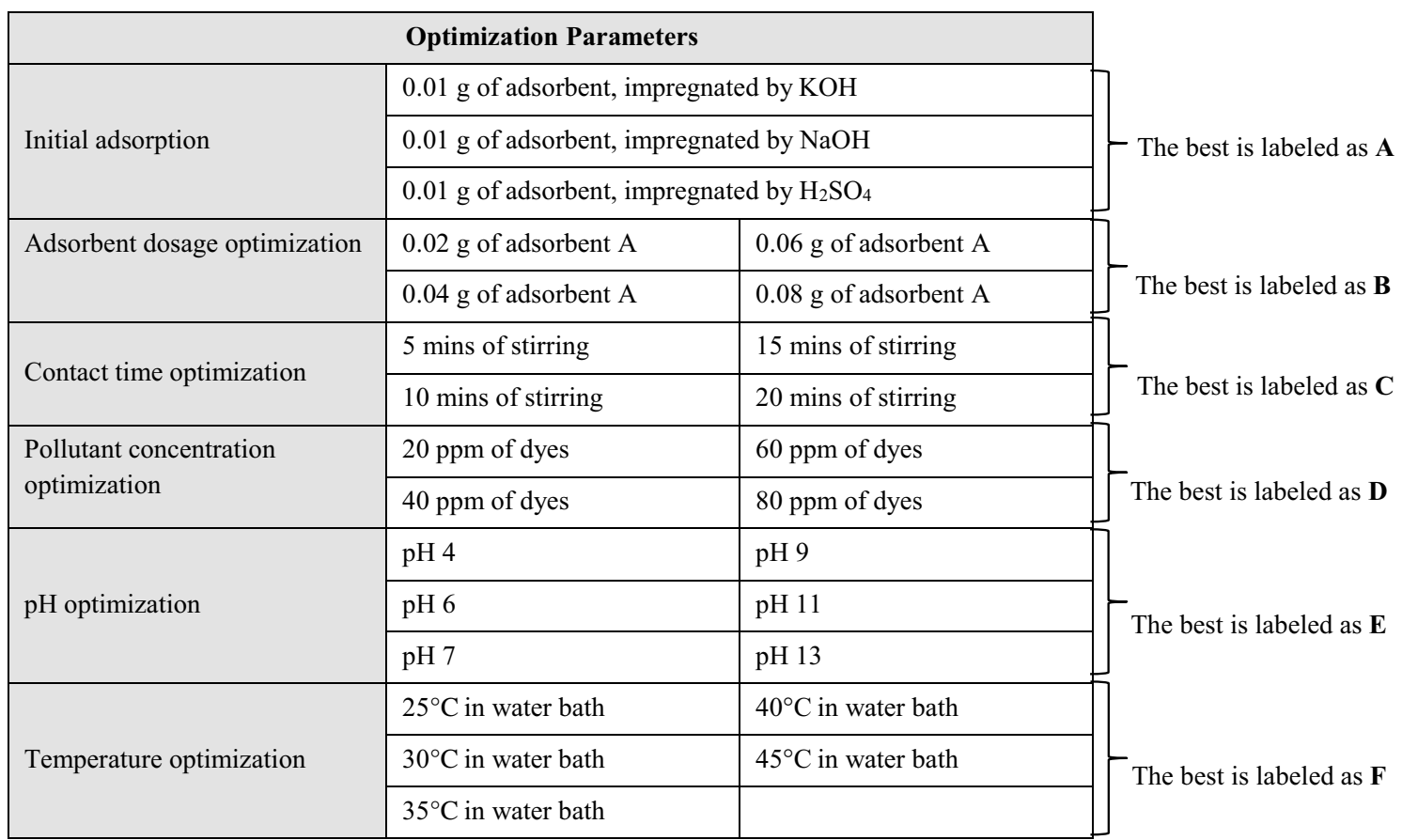

Table 5. Optimization of the adsorption parameters.

$$
q_{e}=\frac{\left(C_{0}-C_{e}\right) V}{M}
$$

where $\mathrm{q} \%$ is the overall removal percentage, $\mathrm{q}_{\mathrm{e}}\left(\mathrm{mg} \mathrm{g}^{-1}\right)$ is the adsorption capacity, $\mathrm{C}_{0}\left(\mathrm{mg} \mathrm{l}^{-1}\right)$ is the initial pollutant concentration, $\mathrm{C}_{\mathrm{e}}\left(\mathrm{mg} \mathrm{l}^{-1}\right)$ is the pollutant concentration after the adsorption process, $\mathrm{V}(\mathrm{l})$ is the solution volume, and $\mathrm{M}(\mathrm{g})$ is the mass of the adsorbent.

Isotherm model analysis. Adsorption isothermal models were analytical and mathematical patterns based on the Langmuir, Freundlich, and Dubinin-Radushkevich models. Using those models, equilibrium was plotted as the solid phase $\left(\mathrm{q}_{\mathrm{e}}\right)$ versus the liquid phase concentration $\left(\mathrm{C}_{\mathrm{e}}\right)$. The models explained the diffusion and the concentration of pollution ${ }^{60,67}$. These data are essential to understand the uptake mechanisms and the interaction between adsorbate and the adsorbents. The results indicated that the removal of dyes by the PAC involved multilayer adsorption uptake on a heterogeneous surface of adsorbate; the amount of adsorbate adsorbed increased infinitely with an increase in concentration ${ }^{99}$.

The Langmuir model, with a linear-plotted $1 / \mathrm{q}_{\mathrm{e}}$ versus $1 / \mathrm{C}$, was determined using Eq. (2):

$$
\frac{1}{q_{e}}=\frac{1}{q_{m}}+\frac{1}{K_{L} q_{m} C_{e}}
$$

where $\mathrm{q}_{\mathrm{e}}$ is the equilibrium adsorbate concentration in solution, $\mathrm{q}_{\mathrm{m}}$ is the maximum adsorption capacity, and $\mathrm{KL}$ is the Langmuir constant in $\mathrm{L} \mathrm{mg}^{-1}$. The Langmuir adsorption isotherm model describes the adsorption sites' homogenous surface and the absence of interactions between the adsorbate molecules. The Freundlich model with linear-plotted $\log \mathrm{q}_{\mathrm{e}}$ versus $\log \mathrm{C}_{\mathrm{e}}$ is shown in Eq. (3):

$$
\log q_{e}=\log K_{f}+\frac{1}{n} \log C_{e}
$$

where $K_{f}$ is an indicator of the adsorption capacity, and $1 / n$ is the adsorption intensity. A linear form of the Freundlich expression yielded the constants $\mathrm{K}_{\mathrm{f}}$ and $1 / \mathrm{n}$.

The Dubinin-Radushkevich isotherm model was conducted to examine the biosorption process's energy in detail, whether the process is physical or chemical. The linearized form of the Dubinin-Radushkevich equation is shown in Eq. $(4)^{31}$.

$$
\ln q_{e}=\ln q_{m}+\beta \varepsilon^{2}
$$

Kinetic model analysis. An analysis was conducted to determine the adsorption kinetics of dyes onto the PAC. The adsorption kinetics for these adsorbents were determined based on the pseudo-first-order, pseudosecond-order, Elovich models, and intraparticle kinetic models. These models were used to analyze the PAC's dye removal process. The adsorption mechanism was chemically explained as the probability of adsorption 
properties, which typically involves monolayer adsorption due to its specific bonding between adsorbates and the surface of the adsorbent ${ }^{99}$. Eq. (5) shows the calculation of the pseudo-first-order model:

$$
\ln \left(q_{e}-q_{t}\right)=\ln \left(q_{e}\right)-k_{1} t
$$

where $\mathrm{q}_{\mathrm{e}}\left(\mathrm{mg} \mathrm{g}^{-1}\right)$ and $\mathrm{q}_{\mathrm{t}}\left(\mathrm{mg} \mathrm{g}^{-1}\right)$ are the amounts of dye removal or adsorbate adsorbed at equilibrium and at time $t ; k_{1}$ is the rate constant of this first-order model. The pseudo-second-order equation is written in linear form as follows (Eq. (6) $)^{60}$.

$$
\frac{1}{q_{t}}=\frac{1}{k_{2} q_{e}^{2}}+\frac{1}{q_{e}} t
$$

where the slope and intercept of $\left(\mathrm{t} / \mathrm{q}_{\mathrm{t}}\right)$ versus $\mathrm{t}$ were used to calculate the pseudo-second-order rate constant $\left(\mathrm{k}_{2}\right)$ and adsorbate adsorbed at equilibrium $\left(\mathrm{q}_{\mathrm{e}}\right)$.

The pseudo-second-order kinetic (Elovich equation) assumed that the real media surfaces were heterogeneous based on their energy. The linear equation is shown in Eq. (7):

$$
q_{t}=k_{i} t^{0.5}+c
$$

where $\mathrm{k}_{\mathrm{i}}$ is the intraparticle diffusion constant, and $\mathrm{c}$ is the intercept. The pseudo-second-order model showed the best fit to the experimental data with the highest squared correlation coefficients of determination $\left(R^{2}=0.999\right)^{100}$.

Thermodynamics study. To calculate the thermodynamic factors that can provide a better understanding of the nature of the adsorption reaction and its feasibility, a Gibbs free energy change $(\Delta \mathrm{G})$, entropy change $(\Delta \mathrm{S})$, and enthalpy change $(\Delta \mathrm{H})$ are required. All of the parameters were calculated at different temperatures, according to Eqs. (8) and (9). T ( $\left.{ }^{\circ} \mathrm{K}\right)$ is the absolute temperature, $\mathrm{K}_{\mathrm{L}}$ is the equilibrium constant, and $\mathrm{R}\left(8.314 \mathrm{~J} \mathrm{~mol} \mathrm{~K}^{-1}\right)$ is the universal gas constant. The $\Delta \mathrm{H}, \Delta \mathrm{S}$, and $\Delta \mathrm{G}$ values were calculated based on the slope and y-intercept of Eq. (10) for both MB and CR:

$$
\begin{gathered}
\Delta G=-\mathrm{RT} \ln K_{L} \\
\Delta G=\Delta H-T \Delta S \\
\ln K=\frac{\Delta S}{R}-\frac{\Delta H}{\mathrm{RT}}
\end{gathered}
$$

lonic strength and regeneration of the PAC. The active sites of the adsorbent surface had ions that affected the adsorption process. To study the stability of the dyes and the adsorbents, the ionic intensity test was applied using $\mathrm{NaCl}$ solution as the electrolyte solution in various concentrations, which are $0.01,0.03,0.05,0.1$, and $0.3 \mathrm{~mol} / \mathrm{L}$.

The adsorbent's ability to regenerate and reuse without significant changes in the adsorption capacity and efficiency played a vital role in reducing the cost of the adsorption process and synthesized adsorbent. To test the reusability and regeneration capability of the material, ten cycles of the adsorption process were conducted at optimum adsorption conditions. Adsorbents were recovered using a centrifuge (Sigma 6-16S, Germany, $8000 \mathrm{rpm}, 10 \mathrm{~min}$ ). After each cycle, the adsorbents were washed and regenerated using $1 \% \mathrm{HCl}$ solution. The regenerated adsorbents were dried in an oven at $60^{\circ} \mathrm{C}$ before each cycle in the adsorption process.

Received: 1 January 2021; Accepted: 8 April 2021

Published online: 21 April 2021

\section{References}

1. Chowdhury, S., Pan, S., Balasubramanian, R. \& Das, P. Date palm based activated carbon for the efficient removal of organic dyes from aqueous environment. Sustain. Agric. Rev. 34, 247-263 (2019).

2. Masoudian, N., Rajabi, M. \& Ghaedi, M. Titanium oxide nanoparticles loaded onto activated carbon prepared from bio-waste watermelon rind for the efficient ultrasonic-assisted adsorption of congo red and phenol red dyes from wastewaters. Polyhedron 173, 114105 (2019).

3. Wang, G., Li, G., Huan, Y., Hao, C. \& Chen, W. Acrylic acid functionalized graphene oxide: High-efficient removal of cationic dyes from wastewater and exploration on adsorption mechanism. Chemosphere 261, 127736 (2020).

4. Yun, J. et al. High efficient dye removal with hydrolyzed ethanolamine-Polyacrylonitrile UF membrane: Rejection of anionic dye and selective adsorption of cationic dye. Chemosphere 259, 127390 (2020).

5. Banch, T. J., Hanafiah, M. M., Alkarkhi, A. F., Amr, S. S. \& Nizam, N. U. Evaluation of different treatment processes for landfill leachate using low-cost agro-industrial materials. Processes. 8, 111 (2020).

6. Bhatnagar, A., Vilar, V. J. P., Botelho, C. M. S. \& Boaventura, R. A. R. Coconut-based biosorbents for water treatment-A review of the recent literature. Adv. Colloid Interfac. 160, 1-15 (2010).

7. Burakov, A. E. et al. Adsorption of heavy metals on conventional and nanostructured materials for wastewater treatment purposes: A review. Ecotox. Environ. Safe. 148, 702-712 (2018).

8. Dullah, H., Malek, M. A. \& Hanafiah, M. M. Life cycle assessment of nile tilapia (oreochromis niloticus) farming in Kenyir Lake Terengganu. Sustainability 12, 2268 (2020).

9. Gupta, V. K. \& Nayak, A. Cadmium removal and recovery from aqueous solutions by novel adsorbents prepared from orange peel and $\mathrm{Fe}_{2} \mathrm{O}_{3}$ nanoparticles. Chem. Eng. J. 180, 81-90 (2012). 
10. Ranjan, B., Pillai, S., Permaul, K. \& Singh, S. Simultaneous removal of heavy metals and cyanate in a wastewater sample using immobilized cyanate hydratase on magnetic-multiwall carbon nanotubes. J. Hazard. Mater. 363, 73-80 (2019).

11. Roccaro, P., Sgro, M. \& Vagliasindi, F. G. A. Removal of xenobiotic compounds from wastewater for environment Protection: treatment processes and costs. Chem. Eng. Trans. 32, 505-510 (2013).

12. Saleh, T. A. \& Gupta, V. K. Column with CNT/magnesium oxide composite for lead (II) removal from water. Environ. Sci. Pollut. Res. 19, 224-1228 (2012).

13. Shaikh, M. M., AlSuhaimi, A., Hanafiah, M. M. \& Alshahateet, S. F. Release of organic contaminants migrating from polyvinyl chloride polymeric into drinking water under three successive stagnant periods of time. Desalin. Water Treat. 149, 105-116 (2019).

14. Al-Raad, A., Hanafiah, M. M., Naje, A. S. \& Ajeel, M. A. Optimized parameters of the electrocoagulation process using a novel reactor with rotating anode for saline water treatment. Environ. Pollut. 265(2), 115049 (2020)

15. Charola, S., Patel, H., Chandna, S. \& Maiti, S. Optimization to prepare porous carbon from mustard husk using response surface methodology adopted with central composite design. J. Clean. Prod. 223, 969-979 (2019).

16. Chen, Y. et al. Application studies of activated carbon derived from rice husks produced by chemical-thermal process -A review. Adv. Colloid Interfac. 163, 39-52 (2011).

17. Hanafiah, M. M., Hashim, N. A., Ahmed, S. T. \& Ashraf, M. A. Removal of chromium from aqueous solutions using a palm kernel shell adsorbent. Desalin. Water Treat. 118, 172-180 (2018).

18. Hanafiah, M. M., Zainuddin, M. F., Mohd Nizam, N. U., Halim, A. A. \& Rasool, A. Phytoremediation of aluminium and iron from industrial wastewater using Ipomoea aquatica and Centella asiatica. Appl. Sci. 10, 3064 (2020).

19. Nizam, N. U. M., Hanafiah, M. M., Mohd Noor, I. \& Abd Karim, H. I. Efficiency of five selected aquatic plants in phytoremediation of aquaculture wastewater. Appl. Sci. 10, 2712 (2020).

20. Rahman, H. A. \& Chin, S. X. Physical and chemical properties of the rice straw activated carbon produced from carbonization and KOH activation processes. Sains Malays. 48, 385-391 (2019).

21. Ashraf, M. A., Balkhair, K. S., Chowdhury, A. J. K. \& Hanafiah, M. M. Treatment of Taman Beringin landfill leachate using the column technique. Desalin. Water Treat. 149, 370-387 (2019).

22. Ashraf, M. A. \& Hanafiah, M. M. Sustaining life on earth system through clean air, pure water, and fertile soil. Environ. Sci. Pollut. Res. 26, 13679-13680 (2019).

23. Al-Raad, A. et al. Treatment of saline water using electrocoagulation with combined electrical connection of electrodes. Processes. 7, 242 (2019).

24. Banch, T. J., Hanafiah, M. M., Alkarkhi, A. F., Amr, A. \& Salem, S. Factorial design and optimization of landfill leachate treatment using tannin-based natural coagulant. Polymers 11, 1349 (2019).

25. Fu, F. \& Wang, Q. Removal of heavy metal ions from wastewaters: a review. J. Environ. Manage. 92, 407-418 (2011).

26. Im, D., Nakada, N., Fukuma, Y. \& Tanaka, H. Effects of the inclusion of biological activated carbon on membrane fouling in combined process of ozonation, coagulation and ceramic membrane filtration for water reclamation. Chemosphere 220, 20-27 (2019).

27. Rybak, M., Drzewiecka, K., Woźniak, M., Ratajczak, I., Joniak, T. Iron-induced behavioural and biochemical responses of charophytes in consequence of phosphates coagulant addition: Threats to lake ecosystems restoration. Chemosphere. 126844 (2020).

28. Yao, F. et al. Electrochemical Cr (VI) removal from aqueous media using titanium as anode: Simultaneous indirect electrochemical reduction of $\mathrm{Cr}(\mathrm{VI})$ and in-situ precipitation of $\mathrm{Cr}$ (III). Chemosphere 260, 127537 (2020).

29. Foroutan, R., Peighambardoust, S. J., Aghdasinia, H., Mohammadi, R. \& Ramavandi, B. Modification of bio-hydroxyapatite generated from waste poultry bone with $\mathrm{MgO}$ for purifying methyl violet-laden liquids. Environ. Sci. Pollut. Res. 27(35), 44218-44229 (2020).

30. Pashaei-Fakhri, S., Peighambardoust, S. J., Foroutan, R., Arsalani, N. \& Ramavandi, B. Crystal violet dye sorption over acrylamide/graphene oxide bonded sodium alginate nanocomposite hydrogel. Chemosphere 270, 129419 (2021).

31. Esvandi, Z., Foroutan, R., Peighambardoust, S. J., Akbari, A. \& Ramavandi, B. Uptake of anionic and cationic dyes from water using natural clay and clay/starch $/ \mathrm{MnFe}_{2} \mathrm{O}_{4}$ magnetic nanocomposite. Surfac. Interfac. 21, 100754 (2020).

32. Foroutan, R. et al. Performance of montmorillonite/graphene oxide/ $\mathrm{CoFe}_{2} \mathrm{O}_{4}$ as a magnetic and recyclable nanocomposite for cleaning methyl violet dye-laden wastewater. Adv. Powder Technol. 31(9), 3993-4004 (2020).

33. Foroutan, R., Peighambardoust, S.J., Esvandi, Z., Khatooni, H. and Ramavandi, B. Evaluation of two cationic dyes removal from aqueous environments using $\mathrm{CNT} / \mathrm{MgO} / \mathrm{CuFe}_{2} \mathrm{O}_{4}$ magnetic composite powder: A comparative study. J. Environ. Chem. Eng. $104752(2020)$

34. Foroutan, R. et al. Calcined alluvium of agricultural streams as a recyclable and cleaning tool for cationic dye removal from aqueous media. Environ. Technol. Innov. 17, 100530 (2020).

35. Foroutan, R., Mohammadi, R., Razeghi, J. \& Ramavandi, B. Performance of algal activated carbon $/ \mathrm{Fe}_{3} \mathrm{O}_{4}$ magnetic composite for cationic dyes removal from aqueous solutions. Algal Res. 40, 101509 (2019).

36. Foroutan, R., Mohammadi, R. \& Ramavandi, B. Elimination performance of methylene blue, methyl violet, and Nile blue from aqueous media using $\mathrm{AC} / \mathrm{CoFe}_{2} \mathrm{O}_{4}$ as a recyclable magnetic composite. Environ. Sci. Pollut. Res. 26(19), 19523-19539 (2019).

37. Bonyadi, Z. et al. Ultrasonic-assisted synthesis of Populus alba activated carbon for water defluorination: application for real wastewater. Korean J. Chem. Eng. 36(10), 1595-1603 (2019).

38. Said, M., Mohammad, A. W., Nor, M. T. M. \& Abdullah, S. Investigation of three pre-treatment methods prior to nanofiltration membrane for palm oil mill effluent treatment. Sains Malays. 44, 421-427 (2015).

39. Liu, D. et al. A green technology for the preparation of high capacitance rice husk-based activated carbon. J. Clean. Prod. 112, $1190-1198$ (2016)

40. Ahmed, M. J. \& Theydan, S. K. Physical and chemical characteristics of activated carbon prepared by pyrolysis of chemically treated date stones and its ability to adsorb organics. Powder Technol. 229, 237-245 (2012).

41. Foo, K. Y. \& Hameed, B. H. Adsorption characteristics of industrial solid waste derived activated carbon prepared by microwave heating for methylene blue. Fuel Process. Technol. 99, 103-109 (2012).

42. Foo, K. Y. \& Hameed, B. H. Coconut husk derived activated carbon via microwave induced activation: Effects of activation agents, preparation parameters and adsorption performance. Chem. Eng. J. 184, 57-65 (2012).

43. Foo, K. Y. \& Hameed, B. H. Textural porosity, surface chemistry and adsorptive properties of durian shell derived activated carbon prepared by microwave assisted $\mathrm{NaOH}$ activation. Chem. Eng. J. 187, 53-62 (2012).

44. Foo, K. Y. \& Hameed, B. H. An overview of dye removal via activated carbon adsorption process. Desalin. Water Treat. 19(1-3), 255-274 (2010).

45. Mopoung, S., Moonsri, P., Palas, W. \& Khumpai, S. Characterization and properties of activated carbon prepared from tamarind seeds by KOH activation for Fe (III) adsorption from aqueous solution. Sci. World J. 2015, 415961 (2015).

46. $\mathrm{Lu}, \mathrm{C}$., $\mathrm{Xu}, \mathrm{S}$. \& Liu, C. The role of $\mathrm{K}_{2} \mathrm{CO}_{3}$ during the chemical activation of petroleum coke with KOH. J. Analyt. Appl. Pyroly. 87(2), 282-287 (2010)

47. Binitha, N. N. \& Sugunan, S. Preparation, characterization and catalytic activity of titania pillared montmorillonite clays. Micropor. Mesopor. Mat. 93, 82-89 (2006). 
48. Mahmoudi, E. et al. Simultaneous removal of congo red and cadmium (II) from aqueous solutions using graphene oxide-silica composite as a multifunctional adsorbent. J. Environ. Sci. 98, 151-160 (2020).

49. Narayanan, D. P., Gopalakrishnan, A., Yaakob, Z., Sugunan, S. \& Narayanan, B. N. A facile synthesis of clay-graphene oxide nanocomposite catalysts for solvent free multicomponent Biginelli reaction. Arabian J. Chem. 13, 318-334 (2020).

50. Gao, L. et al. Simultaneous removal of $\mathrm{NO}$ and $\mathrm{Hg} 0$ from simulated flue gas over $\mathrm{CoOx}-\mathrm{CeO}_{2}$ loaded biomass activated carbon derived from maize straw at low temperatures. Chem. Eng. J. 342, 339-349 (2018).

51. Yu, F., Yiran, S., Mingxuan, Y. \& Jie, M. Adsorption mechanism and effect of moisture contents on ciprofloxacin removal by three-dimensional porous graphene hydrogel. J. Hazard. Mater. 374, 195-202 (2019).

52. Yan, X., Tao, W., Cheng, S., Ma, C., Zhang, Y., Sun, Y. and Kong, X. Layer-by-layer assembly of bio-inspired borate/graphene oxide membranes for dye removal. Chemosphere. 127118 (2020).

53. Hsieh, S. H., Chen, W. J. \& Yeh, T. H. Effect of various amounts of graphene oxide on the degradation characteristics of the ZnSe/ graphene nanocomposites. Appl. Surfac. Sci. 358, 63-69 (2015).

54. Hsieh, S. H. \& Ting, J. M. Characterization and photocatalytic performance of ternary Cu-doped ZnO/graphene materials. Appl. Surfac. Sci. 427, 465-475 (2018).

55. Ramos-Corona, A. et al. Photocatalytic performance of nitrogen doped $\mathrm{ZnO}$ structures supported on graphene oxide for $\mathrm{MB}$ degradation. Chemosphere 236, 124368 (2019).

56. Yang, W. D., Li, Y. R. \& Lee, Y. C. Synthesis of $\mathrm{r}-\mathrm{GO} / \mathrm{TiO}_{2}$ composites via the UV-assisted photocatalytic reduction of graphene oxide. Appl. Surf. Sci. 380, 249-256 (2016).

57. Yousefi, R., Azimi, H. R., Mahmoudian, M. R. \& Basirun, W. J. The effect of defect emissions on enhancement photocatalytic performance of ZnSe QDs and ZnSe/rGO nanocomposites. Appl. Surf. Sci. 435, 886-893 (2018).

58. Olusegun, S. J. \& Mohallem, N. D. Comparative adsorption mechanism of doxycycline and congo red using synthesized kaolinite supported $\mathrm{CoFe} 2 \mathrm{O} 4$ nanoparticles. Environ. Pollut. 260, 114019 (2020).

59. Maneerung, T. et al. Activated carbon derived from carbon residue from biomass gasification and its application for dye adsorption: kinetics, isotherms and thermodynamic studies. Biores. Technol. 200, 350-359 (2016).

60. Wang, J., Zhang, W., Kang, X. \& Zhang, C. Rapid and efficient recovery of silver with nanoscale zerovalent iron supported on high performance activated carbon derived from straw biomass. Environ. Pollut. 255, 113043 (2019).

61. Debnath, S., Maity, A. \& Pillay, K. Impact of process parameters on removal of congo red by graphene oxide from aqueous solution. J. Environ. Chem. Eng. 2, 260-272 (2014).

62. Hu, Y. et al. Dye adsorption by resins: effect of ionic strength on hydrophobic and electrostatic interactions. Chem. Eng. J. 228, 392-397 (2013).

63. Li, Y. et al. Methylene blue adsorption on graphene oxide/calcium alginate composites. Carbohyd. Polym. 95, 501-507 (2013).

64. Ahmad, R. \& Kumar, R. Adsorptive removal of congo red dye from aqueous solution using bael shell carbon. Appl. Surfac. Sci. 257, 1628-1633 (2010).

65. Sayğıll, H. \& Güzel, F. Performance of new mesoporous carbon sorbent prepared from grape industrial processing wastes for malachite green and congo red removal. Chem. Eng. Res. Des. 100, 27-38 (2015).

66. Barkauskas, J., Stankevičienė, I., Dakševič, J. \& Padarauskas, A. Interaction between graphite oxide and congo red in aqueous media. Carbon 49, 5373-5381 (2011).

67. Andelescu, A., Nistor, M. A., Muntean, S. G. \& Rădulescu-Grad, M. E. Adsorption studies on copper, cadmium, and zinc ion removal from aqueous solution using magnetite/carbon nanocomposites. Sep. Sci. Technol. 53(15), 2352-2364 (2018).

68. Muntean, S. G. et al. Combustion synthesis of $\mathrm{Fe} 3 \mathrm{O} 4 / \mathrm{Ag} / \mathrm{C}$ nanocomposite and application for dyes removal from multicomponent systems. Appl. Surf. Sci. 481, 825-837 (2019).

69. Muntean, S.G., Nistor, M.A., Muntean, E., Todea, A., Ianoş, R. and Păcurariu, C. Removal of colored organic pollutants from wastewaters by magnetite/carbon nanocomposites: single and binary systems. J. Chem. 2018 (2018).

70. Paşka, O. M., Păcurariu, C. \& Muntean, S. G. Kinetic and thermodynamic studies on methylene blue biosorption using cornhusk. RSC Adv. 4(107), 62621-62630 (2014).

71. Muntean, S. G., Todea, A., Bakardjieva, S. \& Bologa, C. Removal of non-benzidine direct red dye from aqueous solution by using natural sorbents: Beech and Silver Fir. Desalin. Water Treat. 66, 235-250 (2017).

72. Nicola, R. et al. Highly efficient and fast removal of colored pollutants from single and binary systems, using magnetic mesoporous silica. Chemosphere 261, 127737 (2020).

73. Azizkhani, S. et al. Removal of cadmium (II) by graphene oxide-chitosan adsorbent from aqueous solution. Int. J. Eng. Technol. 7, 5-8 (2018).

74. Kumar, P. S., Ramakrishnan, K., Kirupha, S. D. \& Sivanesan, S. Thermodynamic and kinetic studies of cadmium adsorption from aqueous solution onto rice husk. Braz. J. Chem. Eng. 27, 347-355 (2010).

75. Piccin J.S., Cadaval T.R.S., de Pinto L.A.A., Dotto G.L. Adsorption Isotherms in Liquid Phase: Experimental, Modeling, and Interpretations. In: Bonilla-Petriciolet A., Mendoza-Castillo D., Reynel-Ávila H. (eds) Adsorption Processes for Water Treatment and Purification. Springer, Cham, Switzerland, (2017).

76. Dotto G.L., Salau N.P.G., Piccin J.S., Cadaval T.R.S., de Pinto L.A.A. Adsorption Kinetics in Liquid Phase: Modeling for Discontinuous and Continuous Systems. In: Bonilla-Petriciolet A., Mendoza-Castillo D., Reynel-Ávila H. (eds) Adsorption Processes for Water Treatment and Purification. Springer, Cham, Switzerland, (2017).

77. Hu, X. J. et al. Adsorption of chromium (VI) by ethylenediamine-modified cross-linked magnetic chitosan resin: isotherms, kinetics and thermodynamics. J. Hazard. Mater. 185, 306-314 (2011).

78. Hussein, F. H., Halbus, A. F., Lafta, A. J. \& Athab, Z. H. Preparation and characterization of activated carbon from Iraqi Khestawy date palm. J. Chem. 2015, 295748 (2015).

79. Pathania, D., Sharma, S. \& Singh, P. Removal of methylene blue by adsorption onto activated carbon developed from Ficus carica bast. Arab. J. Chem. 10, 1445-1451 (2017).

80. Bedin, K. C., Martins, A. C., Cazetta, A. L., Pezoti, O. \& Almeida, V. C. KOH-activated carbon prepared from sucrose spherical carbon: Adsorption equilibrium, kinetic and thermodynamic studies for methylene blue removal. Chem. Eng. J. 286, 476-484 (2016).

81. Ashour, S. S. Kinetic and equilibrium adsorption of methylene blue and remazol dyes onto steam-activated carbons developed from date pits. J. Saudi Chem. Soc. 14, 47-53 (2010).

82. Reddy, K. S. K., Al Shoaibi, A. \& Srinivasakannan, C. A comparison of microstructure and adsorption characteristics of activated carbons by $\mathrm{CO}_{2}$ and $\mathrm{H}_{3} \mathrm{PO}_{4}$ activation from date palm pits. New Carbon Mater. 27, 344-351 (2012).

83. Foo, K. Y. \& Hameed, B. H. Preparation of activated carbon from date stones by microwave induced chemical activation: Application for methylene blue adsorption. Chem. Eng. J. 170, 338-341 (2011).

84. Islam, M. A., Tan, I. A. W., Benhouria, A., Asif, M. \& Hameed, B. H. Mesoporous and adsorptive properties of palm date seed activated carbon prepared via sequential hydrothermal carbonization and sodium hydroxide activation. Chem. Eng. J. 270, 187-195 (2015)

85. Mahmoudi, K., Hosni, K., Hamdi, N. \& Srasra, E. Kinetics and equilibrium studies on removal of methylene blue and methyl orange by adsorption onto activated carbon prepared from date pits-A comparative study. Korean J. Chem. Eng. 32, 274-283 (2015). 
86. Daoud, M., Benturki, O., Kecira, Z., Girods, P. \& Donnot, A. Removal of reactive dye (BEZAKTIV Red S-MAX) from aqueous solution by adsorption onto activated carbons prepared from date palm rachis and jujube stones. J. Mol. Liq. 243, 799-809 (2017).

87. Yu, K. L. et al. Adsorptive removal of cationic methylene blue and anionic Congo red dyes using wet-torrefied microalgal biochar: Equilibrium, kinetic and mechanism modeling. Environ. Pollut. 272, 115986 (2021).

88. Yağmur, H. K. \& Kaya, İ. Synthesis and characterization of magnetic $\mathrm{ZnCl} 2$-activated carbon produced from coconut shell for the adsorption of methylene blue. J. Mol. Struct. 1232, 130071 (2021).

89. Omorogie, M. O. et al. Activated carbon from Nauclea diderrichii agricultural waste-a promising adsorbent for ibuprofen, methylene blue and $\mathrm{CO}_{2}$. Adv. Powder Technol. 32(3), 866-874 (2021).

90. Paluri, P., Ahmad, K.A. and Durbha, K.S. Importance of estimation of optimum isotherm model parameters for adsorption of methylene blue onto biomass derived activated carbons: Comparison between linear and non-linear methods. Biomass Convers. Biorefin. 1-18 (2020).

91. Bello, M. O., Abdus-Salam, N., Adekola, F. A. \& Pal, U. Isotherm and kinetic studies of adsorption of methylene blue using activated carbon from ackee apple pods. Chem. Data Collect. 31, 100607 (2021).

92. Batool, A. \& Valiyaveettil, S. Chemical transformation of soya waste into stable adsorbent for enhanced removal of methylene blue and neutral red from water. J. Environ. Chem. Eng. 9(1), 104902 (2021).

93. Zhou, D. et al. Activated carbons prepared via reflux-microwave-assisted activation approach with high adsorption capability for methylene blue. J. Environ. Chem. Eng. 9(1), 104671 (2021).

94. Bello, O. S. \& Banjo, S. Equilibrium, kinetic, and quantum chemical studies on the adsorption of Congo red using Imperata cylindrica leaf powder activated carbon. Toxicol. Environ. Chem. 94, 1114-1124 (2012).

95. Belhachemi, M. \& Addoun, F. Adsorption of congo red onto activated carbons having different surface properties: studies of kinetics and adsorption equilibrium. Desalin. Water Treat. 37, 122-129 (2012).

96. Lawal, I. A., Chetty, D., Akpotu, S. O. \& Moodley, B. Sorption of congo red and reactive blue on biomass and activated carbon derived from biomass modified by ionic liquid. Environ. Nanotechnol. Monitor. Manag. 8, 83-91 (2017).

97. Lafi, R., Montasser, I. \& Hafiane, A. Adsorption of congo red dye from aqueous solutions by prepared activated carbon with oxygen-containing functional groups and its regeneration. Adsorpt. Sci. Technol. 37(1-2), 160-181 (2019).

98. Stjepanović, M. et al. From waste to biosorbent: removal of Congo red from water by waste wood biomass. Water 13(3), 279 (2021).

99. Manikam, M. K., Halim, A. A., Hanafiah, M. M. \& Krishnamoorthy, R. R. Removal of ammonia nitrogen, nitrate, phosphorus and COD from sewage wastewater using palm oil boiler ash composite adsorbent. Desalin. Water Treat. 149, 23-30 (2019).

100. Wahab, M. A., Jellali, S. \& Jedidi, N. Ammonium biosorption onto sawdust: FTIR analysis, kinetics and adsorption isotherms modelling. Bioresource Technol. 101, 5070-5075 (2010).

\section{Acknowledgements}

This study was supported by the UKM research grants (DIP-2019-001 and GUP-2020-034). We would like to thank the Research Centre for Sustainable Process Technology (CESPRO), UKM for providing laboratory services and facilities to conduct this research. Thank you to undergraduate students, Tharshini Mani and Foong Wei Lun for conducting the preliminary analysis.

\section{Author contributions}

N.U.M.N.: Investigation, formal analysis, writing—original draft. M.M.H.: Writing_original draft, supervision, project administration, funding acquisition, writing - review \& editing. E.M.: Methodology, supervision, writing-review \& editing. A.A.H.: Methodology, writing—review \& editing. A.W.M.: Supervision, writing—review \& editing.

\section{Competing interests}

The authors declare no competing interests.

\section{Additional information}

Correspondence and requests for materials should be addressed to M.M.H.

Reprints and permissions information is available at www.nature.com/reprints.

Publisher's note Springer Nature remains neutral with regard to jurisdictional claims in published maps and institutional affiliations.

Open Access This article is licensed under a Creative Commons Attribution 4.0 International License, which permits use, sharing, adaptation, distribution and reproduction in any medium or format, as long as you give appropriate credit to the original author(s) and the source, provide a link to the Creative Commons licence, and indicate if changes were made. The images or other third party material in this article are included in the article's Creative Commons licence, unless indicated otherwise in a credit line to the material. If material is not included in the article's Creative Commons licence and your intended use is not permitted by statutory regulation or exceeds the permitted use, you will need to obtain permission directly from the copyright holder. To view a copy of this licence, visit http://creativecommons.org/licenses/by/4.0/.

(c) The Author(s) 2021 